\title{
¿UN PROYECTO QUIMÉRICO? SUMINISTROS FORESTALES DESDE LOS PIRINEOS OCCIDENTALES PARA LA REAL ARMADA EN EL SIGLO XVIII ${ }^{1}$
}

\section{A Chimeric project? Forest supplies from Western Pyrenees for the Spanish Royal Navy in the 18th century}

\author{
Álvaro ARAGÓN-RUANO \\ Universidad del País Vasco \\ alvaro.aragon@ehu.eus \\ ORCID: https://orcid.org/0000-0003-0594-6383
}

\section{Óscar RIEZU ELIZALDE}

Universidad de Navarra

oriezu@unav.es

Fecha de recepción: 21/10/2020

Fecha de aceptación: 03/06/2021

\section{INTRODUCCIÓN}

La explotación de los recursos forestales experimentó una progresiva intensificación a lo largo de la Edad Moderna, en el marco de una «economía orgánica» como era la europea. La Monarquía hispánica contaba con una importante riqueza forestal, si bien el desarrollo y expansión de las actividades productivas pusieron cerco a los bosques peninsulares. Las necesidades de la Real Armada crearon la idea

1. Este trabajo se engloba en el Grupo de Investigación Consolidado del Sistema Universitario Vasco País Vasco, Europa y América: Vínculos y Relaciones Atlánticas (IT1241-19) y se enmarca en el proyecto I + D del Ministerio de Ciencia, Innovación y Universidades «Guerra, Estado y Sociedad. La movilización de recursos militares en la construcción de la Monarquía Española en el siglo XVIII» (PGC2018-096194-B-I00). 
ÁLVARO ARAGÓN-RUANO Y ÓSCAR RIEZU ELIZALDE

¿UN PROYECTO QUIMÉRICO? SUMINISTROS FORESTALES DESDE LOS PIRINEOS

OCCIDENTALES PARA LA REAL ARMADA EN EL SIGLO XVIII

de escasez y de necesidad de conservación - algo común a todas las monarquías europeas del momento-, si bien, tras ello, lo que realmente existía era un intento por tener un mayor control y mejor acceso a los recursos forestales, la mayor parte de ellos en manos de comunidades rurales y situados en zonas de difícil acceso. Los discursos en torno a una «permanente crisis» de madera en Europa se convirtieron en un elemento estructural que, sin base empírica real, porque muchos se referían al futuro y no al presente, pretendían la regulación de los bosques. Es difícil, por tanto, hablar de una escasez de madera generalizada en Europa antes de 1750, si bien a partir de 1820 parece ya un hecho consecuencia, por ejemplo, de la expansión experimentada por las marinas europeas, que para finales del siglo XVIII contaban ya con 3'5 millones de toneladas, para lo que fueron precisos en torno a 10'3 millones de metros cúbicos de roble (Warde, 2006: 39-41 y 2015: 138-140 y 146-159).

El aprovechamiento de los recursos madereros pirenaicos contaba ya con una larga trayectoria para cuando en el siglo XVIII las necesidades de la Armada hispánica, en el contexto del programa de rehabilitación iniciado por los Borbones, devolvieron esta amplia región natural a la agenda de los secretarios de Marina (Valdez-Bubnov, 2011). La presencia de importantes astilleros en el área costera vasca, tanto en Vizcaya y Guipúzcoa, como en el Labort, hicieron de los bosques vascos y navarros un centro de explotación maderera de importancia ya desde los primeros tiempos de la Edad Moderna (Aragón, 2001). Durante los siglos XVI y XVII fue habitual la extracción de madera de pino, hacia Zaragoza para la construcción de edificios, de roble para la construcción de navíos y de haya para la confección de remos, desde los montes del País Vasco, del norte de Navarra, principalmente Cinco Villas, y de los valles de Salazar o Roncal, destinados a las galeras mediterráneas, a través de Tortosa, a los navíos que se dirigían a Terranova y a navíos extranjeros ${ }^{2}$.

A partir del siglo XVIII, con el advenimiento de la dinastía borbónica, y los programas de restauración del poderío naval español iniciados por Patiño y continuados por Ensenada, esta área geográfica y sus riquezas naturales volvieron a ser objeto de interés para la corona. En un intento por reducir la fuga de capitales que suponía la compra de pertrechos navales en el extranjero, las autoridades navales trataron de explotar los abundantes recursos forestales y madereros existentes en los territorios peninsulares. Pero chocaron con una doble realidad: dichas riquezas naturales no les pertenecían de hecho ni de derecho y debían negociar su «cesión» con las comunidades locales y las instituciones provinciales; se hallaban situados en áreas geográficas intrincadas, de difícil acceso, con una orografía complicada, a lo que se sumaba el escaso desarrollo de las vías de comunicación disponibles en la península, que dificultaban sobremanera su localización, extracción y transporte hasta los reales arsenales.

2. Archivo General de Navarra (AGN), Procesos 73971, 21341 y 229556; y Tribunales Reales, Archivo Secreto, Tit. 4, Fajo 1, N. 41 y 84. 
ÁLVARO ARAGÓN-RUANO Y ÓSCAR RIEZU ELIZALDE

¿UN PROYECTO QUIMÉRICO? SUMINISTROS FORESTALES DESDE LOS PIRINEOS

OCCIDENTALES PARA LA REAL ARMADA EN EL SIGLO XVIII

Fue precisamente esa lejanía entre la propia Monarquía y sus súbditos, su limitación técnica y la imposibilidad de llegar a todos los rincones lo que obligó a la corona a echar mano, en ocasiones, de intermediarios particulares. En la mayoría de los casos, la firma de asientos para la explotación de recursos en dichas áreas se estableció con personas originarias de ellas o que mantenían un contacto cercano, por motivos familiares o económicos. El conocimiento que dichas personas tenían de la realidad geográfica, social, económica, política y jurisdiccional de dichas áreas facilitó su labor, aunque esta no estuvo exenta de enfrentamientos y conflictos con las comunidades locales. Cuando la Monarquía - no se debe olvidar, compuestaintentó acceder directamente a dichos recursos a través de sus propios funcionarios, también se vio obligada a buscar la colaboración de intermediarios locales. Dicha colaboración y las redes de extracción, transporte y elaboración de piezas y pertrechos navales que entretejieron, permitieron que las riquezas naturales de los Pirineos, de mejor o peor manera - ese es un aspecto que debería ser analizado en próximas investigaciones (Aragón, Reichert y Wing, 2019) - , llegasen a su destino, los astilleros de Guarnizo y Bilbao y los reales arsenales de Ferrol, Cádiz y Cartagena.

En consecuencia, lo que pretende la presente investigación es conocer quiénes fueron esos asentistas, cómo organizaron la explotación y transporte de los recursos, qué redes establecieron, qué conflictos hubieron de afrontar y, en definitiva, qué beneficios obtuvieron de su labor. A pesar de los obstáculos, dificultades y costos a los que tuvieron que hacer frente, en la mayoría de los casos cumplieron con el cometido al que se habían comprometido, es decir, las maderas llegaron a los reales arsenales, pero, ¿a qué precio? A través del caso concreto de dos de estos asentistas trataremos de calibrar cuál fue el objetivo final de dichos personajes, si fue meramente económico o, por el contrario, fue más bien sociopolítico.

Para ello, se ha hecho uso de un variado elenco de fuentes documentales, tanto en archivos provinciales, caso del Archivo Histórico de la Diputación de Bizkaia, el Archivo General de Gipuzkoa, el Archivo del Territorio Histórico de Álava, los fondos de la Fundación Sancho el Sabio, el Archivo General de Navarra o el Archivo Histórico Provincial de Zaragoza, como en archivos municipales vascos y navarros, sin renunciar, por supuesto, a los archivos nacionales, como el Archivo de la Real Chancillería de Valladolid o el Archivo de la Corona de Aragón, o a algunos archivos privados, como el de la Casa Gambra. El trabajo aquí presentado está organizado en un primer apartado en el que se profundizará en la organización de la explotación y transporte de los recursos, un segundo en el que se analizarán las dificultades y conflictos a los que tuvieron que hacer frente los asentistas, para, finalmente, en un capítulo final, valorar la participación concreta de dos asentistas que desarrollaron su actividad en los montes vascos y navarros y el impacto o repercusión que ello tuvo en sus vidas y haciendas. 
ÁLVARO ARAGÓN-RUANO Y ÓSCAR RIEZU ELIZALDE

¿UN PROYECTO QUIMÉRICO? SUMINISTROS FORESTALES DESDE LOS PIRINEOS

OCCIDENTALES PARA LA REAL ARMADA EN EL SIGLO XVIII

\section{UNA TUPIDA RED. LA EXTRACCIÓN DE LOS RECURSOS Y SU TRANSPORTE DESDE LOS BOSQUES A LOS REALES ARSENALES}

La política de extracción de recursos naturales que llevó a cabo la Monarquía hispánica, sobre todo en lo que se refiere a la Península ibérica, estuvo marcada por una cierta improvisación (Baudot, 2019: 5; Pérez-Crespo, 1992; Sánchez y Roda, 2018). No existió un planificación estratégica de explotación de los recursos forestales, lo que provocó una cierta discontinuidad en la extracción desde las diferentes áreas ricas en bosques y madera, consecuencia de los cambios de coyuntura en la política internacional, lo que afectaba a la llegada de recursos desde el extranjero, o de los cambios de política adoptada por el secretario de Marina de turno. Eso es lo que explica que los bosques del País Vasco o Navarra no fuesen explotados con continuidad, sino en función de las coyunturas. La primera mitad del siglo XVIII asistió al fortalecimiento del astillero de Guarnizo, que se abasteció principalmente desde los montes cántabros y asturianos, aunque los montes de Aramayona y Altube (Álava) tuvieron un protagonismo importante, al menos en las tres primeras décadas. A partir de los años treinta el arsenal del Ferrol alternó la recepción de maderas desde Galicia, Asturias y Cantabria, con la llegada de materiales desde el País Vasco y la Navarra atlántica. De hecho, a partir de 1766, cuando la Real Compañía Guipuzcoana de Caracas se hizo con el asiento de explotación y transporte de maderas para el arsenal del Ferrol, ante el agotamiento de los montes cantábricos, los bosques vascos y navarros volvieron a adquirir una importancia capital; se ha calculado que desde Navarra la Real Compañía de Caracas, extrajo entre 1766 y 1782363.542 codos cúbicos, por valor de 19,5 millones de reales (Merino, 1981; Vázquez, 2018).

Si bien en el caso de los montes vascos se percibe una mayor continuidad en su explotación, en el caso de los bosques de la cordillera pirenaica navarra hubo dos momentos álgidos: el primer y el último tercio del siglo XVIII; entre los años treinta y los setenta del Setecientos apenas tenemos noticias de la explotación de los pinabetes pirenaicos para la Real Armada. Es más, parece que desde el asiento de Goyeneche y Vidarte, no se habían vuelto a enviar mástiles ni tablazón hasta Tortosa y que las bondades de esta madera se habían olvidado, pues en 1769 Julián de Arriaga, secretario de Estado de Marina e Indias, pidió al virrey de Navarra el corte de diferentes muestras de madera de pino de los Pirineos para las carenas de barcos y el envío al Ferrol de un cargamento de tablazón y perchas de pino. Parece ser que las muestras enviadas fueron aceptadas y la calidad de las maderas pirenaicas despertó el interés de las autoridades de Marina, pues a partir de ese momento el Pirineo navarro volvió a ser explotado con intensidad, como se verá más adelante.

El siglo XVIII era inaugurado con la construcción de seis navíos de línea, siguiendo el esquema marcado por Antonio Gaztañeta en los astilleros de Pasajes, de la mano de Simón Acelain. Sin embargo, la invasión de las tropas de la Cuádruple Alianza, al mando del duque de Berwick, y la consiguiente destrucción de dichos barcos, hizo que la construcción de navíos para el rey se desplazara lejos de la frontera, desde Guipúzcoa a Cantabria. El propio Antonio Gaztañeta fue elegido para la 
gestión de seis nuevos navíos de línea en el astillero de Guarnizo, siendo el encargado de llevar a cabo tal tarea Bernardo Cambi - que venía de construir tres navíos de línea en San Feliú de Guixols (Baudot, 2019: 20, 25, 38-39) -, siendo Bartolomé José Ortiz de Urbina Ruiz de Zurbano el encargado de toda la gestión financiera. La mayor parte de la madera procedía de los montes de Asturias y Cantabria, siendo embarcada en San Vicente de la Barquera rumbo a Guarnizo (el total de tablas que llegaron a Santoña y Guarnizo para la construcción de los tres navíos fue de unas 15.000), pero en el año 1723 se acudió a los montes de Altube y Aramayona, donde entre marzo y julio se llevaron a cabo las labores de corte y transporte hasta el ribero de Bilbao de tablas y piezas de roble: en los montes de Aramayona se cortaron 700 árboles, que fueron aserrados in situ por una cuadrilla o lantegui de 160 carpinteros, obteniendo 1.627 tablas y en Altube se labraron corbatones y otras maderas. Dichos materiales fueron transportados por una compañía de carreteros, con 30 carros, con la que Urbina firmó una contrata, hasta los puertos de Bilbao y Asua, por 132.436 reales y 5 maravedís de vellón, menos 3.000 reales del valor de la astilla de las tablas que le vendió a uno de ellos. Por mar las maderas fueron transportadas por una flotilla de barcos de Somorrostro hasta Guarnizo.

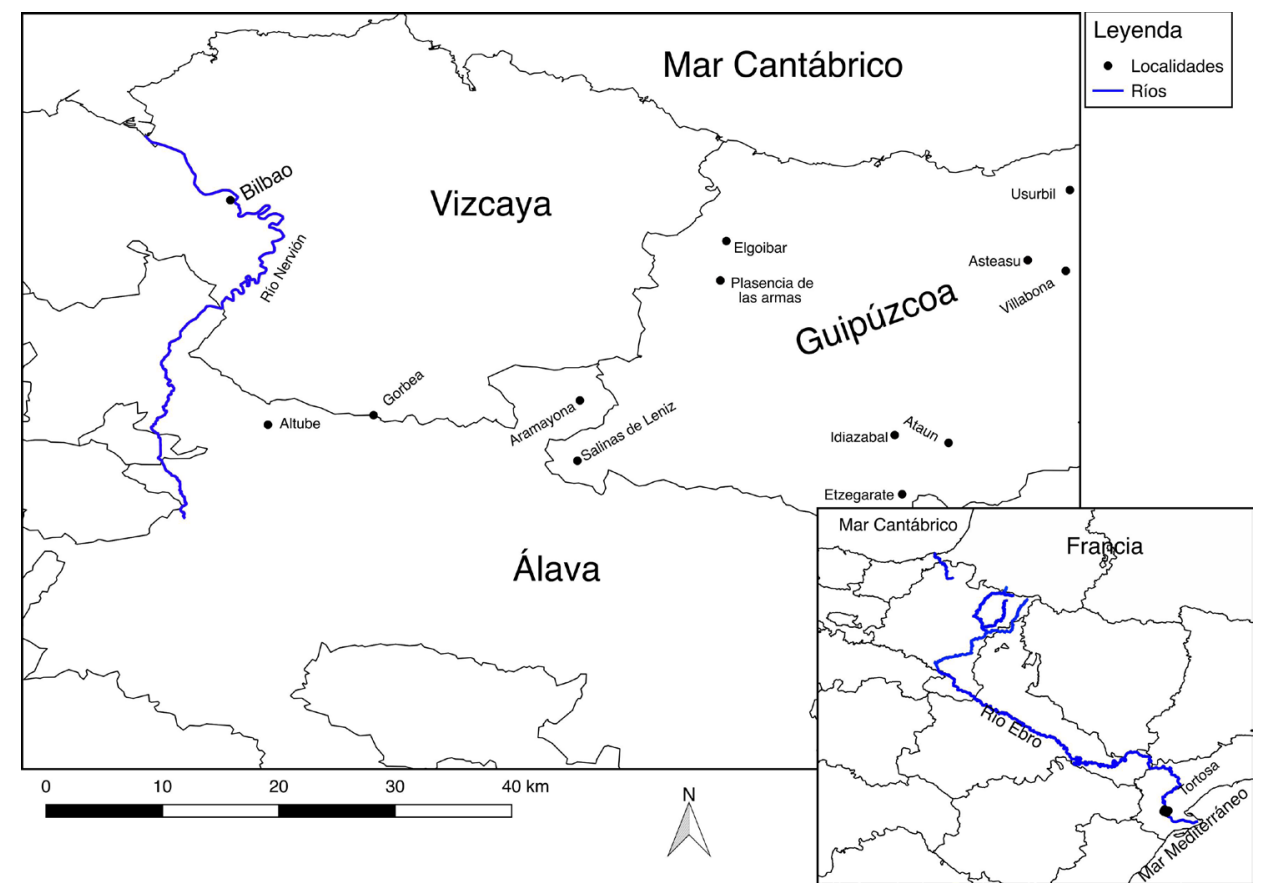

MAPA 1. Zonas de extracción de maderas desde los territorios vascos (autor: Óscar Riezu Elizalde). 
ÁLVARO ARAGÓN-RUANO Y ÓSCAR RIEZU ELIZALDE

¿UN PROYECTO QUIMÉRICO? SUMINISTROS FORESTALES DESDE LOS PIRINEOS

OCCIDENTALES PARA LA REAL ARMADA EN EL SIGLO XVIII

Los seis navíos nunca fueron construidos por Cambi, únicamente dos de ellos fueron finalizados, el San Luis y el San Fernando, quedando un tercero, el San Felipe, a medias. Cambi fue fulminantemente destituido y sufrió un juicio de residencia, acusado del desvío de capitales. Sin embargo, finalmente se demostró que no había desviado ni un solo real de lo asignado y que todo se había invertido en la construcción de los mencionados tres navíos de 70 cañones. Es muy interesante el alegato que el propio Urbina realizó sobre la difícil labor de Cambi, pues sintetiza de alguna forma los males que aquejaron al programa de explotación de recursos de la Monarquía hispánica, incluso una vez establecidos los reales arsenales. Según Urbina, el asiento de Bernardo Cambi no pudo completarse, por la enormidad del proyecto, «la distinta inteligencia y conocimiento en que este emprehendedor estuvo al tiempo de contraer la obligación y los accidentes que sobrevinieron en el curso de la fabrica que motiuaron a crecidos gastos....». Cambi emprendió el proyecto con la idea de que la construcción de los navíos seguiría las mismas reglas que se habían practicado en el asiento catalán. Más aún, aceptó el proyecto con la convicción de que el astillero estaría en condiciones, habría abundancia de materiales cerca del mismo, la maestranza sería hábil y que «...le seria el país fauorable y sin mas dispendio del que tubo en Cathalunia en emprehender la construcción». Sin embargo, cuando llegó no había astillero y tuvo que duplicar los gastos para acondicionarlo, «...por falta de conocimiento de las personas que dirigían esta idea», hubo de construir los alojamientos para la maestranza de carpinteros, las fraguas y demás oficinas, tuvo que ir a una distancia de entre 4 y 8 leguas a buscar los materiales y se le obligó a utilizar los montes de Altube y Aramayona, que distaban 30 leguas, «contra raçon y sin ninguna necesidad».

Más aún, "Como en las montañas estaua oluidada la construcción y eran pocos los naturales que se acordauan de las tiras de madera, parecio a los carreteros vna obra imposible, fue preciso a este asentista para vencer el temor y ninguna practica de los carreteros pagar por las conducciones de madera mas precios excesiuos...». Los caminos no existían y hubo de construirlos a su propio cargo. Los carpinteros hubieron de ser reclutados en Guipúzcoa, distante 34 leguas del astillero, «con crecidos jornales y nunca practicados socorros en medio de que no era sobresaliente, pues los buenos carpinteros ninguno quiso salir de su casa por tener qué trauajar en ella como por no asegurarse de la permanencia en este nueuo establecimiento». Por último, la construcción de los navíos también fue muy complicada y bien diferente de la practicada en Cataluña. Los materiales que se le entregaron no cumplían las condiciones adecuadas, porque además de la mala calidad, estaban cortados para barcos distintos a los proyectados por Gaztañeta. Incluso los materiales que él mandó cortar, llegaron únicamente desbastados, sin corteza, por lo que hubo que duplicar 
ÁLVARO ARAGÓN-RUANO Y ÓSCAR RIEZU ELIZALDE

¿UN PROYECTO QUIMÉRICO? SUMINISTROS FORESTALES DESDE LOS PIRINEOS

OCCIDENTALES PARA LA REAL ARMADA EN EL SIGLO XVIII

los gastos, tanto en la conducción como en la labra en los astilleros, de forma que «...de seis que vienen del monte las quatro son rechazadas...»3.

En los Pirineos navarros fue en la década de los años ochenta del siglo XVII cuando se empezaron a establecer los primeros asientos para sacar madera para la Marina de una forma masiva. No obstante, ya en 1639 Pascual de Atocha, vecino de San Sebastián, aunque originario de Garde, ofertó la conducción de mástiles y remos a Tortosa para ser utilizados en los astilleros de Barcelona, a donde parece que llegaron 300 árboles, o en 1659, junto a Rafael Jerónimo y Juan Soroa, maestros mayores de fábricas de la Armada del Océano y de Guipúzcoa, respectivamente, reconoció los bosques del Pirineo navarro y aragonés e hizo una nueva propuesta al Consejo de Indias. En 1676-1677, su viuda Gracia de Atocha presentó otro proyecto, que no salió adelante por los conflictos jurisdiccionales con la Corona de Aragón y los contrafueros que la propuesta planteaba ${ }^{4}$. Entre 1678-1680 y 1681-1691 Lorenzo de la Bastida y Juan Francisco Miranda, vecinos de Salvatierra de Esca, establecieron sendos asientos para cortar madera en Navarra, Aragón, Cataluña y Valencia. Sin embargo, antes de que acabara el plazo establecido, fueron relevados. En 1695 Antonio Oset, vecino de Salvatierra de Esca, y Domingo Rocatallada, vecino de Hecho, establecieron escritura de convenio con la villa de Isaba por diez años, para explotar desde 1696 el pinar de Ardibide Soroa y extraer de él 1.700 maderos, que transportarían hasta Tortosa ${ }^{5}$. Pero en el intervalo, en 1697, Daniel Vanheden o Van Eden, quien ya contaba con una amplia experiencia en el aprovisionamiento de la corona, estableció un asiento por treinta años para la provisión de mástiles, maderas, brea, alquitrán y tablazón. Un año después, en 1698, se unieron a él, dos navarros, Juan de Goyeneche y su apoderado, José Vidarte, esto es, personas de la tierra que a través de la movilización de sus redes podían facilitar la extracción de las maderas y garantizar el éxito del proyecto. Finalmente, en 1699 Vanheden se desmarcó y quedaron al frente del mismo Goyeneche y Vidarte, firmando contrata con el concejo de Isaba para la extracción de los árboles del monte Maze, que era comunal. Ese mismo año Oset hizo desistimiento de contrata, pasándosela a Vidarte, quien le abonó los 2.000 reales de a ocho que le había costado acondicionar y limpiar el río (Sanz Ayánz, 2004: 95-103)6.

La cabeza visible del asiento era Juan de Goyeneche, sin embargo, quien estaba a pie de obra, en Navarra, encargado de llevar a buen puerto el proyecto, ocupado

3. Archivos de la Fundación Sancho el Sabio, Fondo Archivo Marqués de la Alameda, Sección URBINA, C.72, N.10; Archivo del Territorio Histórico de Álava (ATHA), DH-16964, DH-1225-16 y DH-1233-10.

4. Archivo de la Corona de Aragón (ACA), Consejo de Aragón, Legajos 0058, 0074, n. ${ }^{\circ}$ 003,0076, n. $^{\circ} 002$ y 0078, n. $^{\circ} 002$.

5. AGN, Procesos 91340.

6. AGN, Procesos 91340, 190449, 204852 y 204876. 
ÁLVARO ARAGÓN-RUANO Y ÓSCAR RIEZU ELIZALDE

¿UN PROYECTO QUIMÉRICO? SUMINISTROS FORESTALES DESDE LOS PIRINEOS

OCCIDENTALES PARA LA REAL ARMADA EN EL SIGLO XVIII

en cada uno de los detalles, era José Vidarte. Para las cuestiones administrativas y las relaciones con el Reino de Navarra y los valles y villas pirenaicas, Goyeneche disponía de otros dos apoderados: su hermano Tomás de Goyeneche y Juan Gastón de Iriarte (Castellano, 2007; Aquerreta, 2000). A su vez, Vidarte contaba con colaboradores como Francisco de Mondragón, natural de Aoiz, que ya había colaborado con Daniel Vanheden y era el encargado del pago por adelantado de salarios y jornales, para lo que, en ocasiones, hubo de pedir prestado el dinero. Mondragón se ocupaba de contratar a los cuadrilleros, personajes originarios de los valles del entorno, quienes conformaban a su gusto las cuadrillas, también entre los habitantes de los valles circundantes, a los que conocían o con los que llevaban trabajando tiempo; en caso de falta de personal, los cuadrilleros acudían al reino de Aragón o incluso a Francia. Dichos cuadrilleros eran quienes realizaban el pago de jornales y daban la lista de operarios que trabajaban cada día. Por último, el propio Mondragón seguía a los almadieros en su viaje a Tortosa, abasteciéndoles de víveres y auxiliándoles en todo lo necesario ${ }^{7}$.

Como ya adelantábamos, la Real Compañía Guipuzcoana de Caracas en 1766 firmó un asiento con la corona para el aprovisionamiento de madera y tablazón desde los montes vasco-navarros para los reales arsenales de Ferrol, activo hasta 1782. La extracción de las maderas desde los montes vascos y navarros estaba al cargo del propio director de la compañía - primero Juan Antonio Claessens y después José Agustín de Zuaznabar - . Ambos operaron desde San Sebastián, sede de la compañía, desde donde controlaban la obtención de maderas procedentes de Guipúzcoa, Vizcaya y Navarra, por medio de contratas; no obstante, en ocasiones viajaban a Santesteban, donde se alojaban y gestionaban todas las cuestiones urgentes relativas a los montes del Bidasoa (Aragón, 2001: 121). En Navarra, el director de la compañía comisionaba a diferentes empleados, caso de Juan Bautista Iruretagoyena, ayudante de construcciones de la Real Armada, o a José Garay y José Mutiozabal para que llevasen a cabo la compra de los árboles adecuados. Estos personajes tenían cierta raigambre en el área de explotación, es decir, eran originarios de ella o conocían - por su relación laboral o mercantil - a personas conocedoras del entorno. De hecho, a los mencionados comisionados se les recomendó en 1766 que contratasen carpinteros navarros, del orden de 150 a 200, muchos de los cuales llevaban años trabajando en los astilleros de Ferrol, Guarnizo y Cádiz ${ }^{8}$.

El número de boyerizos y yuntas de bueyes que trabajaban en el transporte de las tablas o troncos desde los montes del Bidasoa hasta Santesteban o en su caso hasta el puerto de Pasajes, era variable, aunque en 1786 rondaba entre los 250 y 320.

7. AGN, Procesos 32182.

8. AGN, Procesos 49830; Montes, Legajo 1, Carpeta 49, Tribunales Reales, Archivo Secreto, Tit. 4, Fajo 2, N. 12 y Tit. 33, Fajo 1, N. 1. 
ÁLVARO ARAGÓN-RUANO Y ÓSCAR RIEZU ELIZALDE

¿UN PROYECTO QUIMÉRICO? SUMINISTROS FORESTALES DESDE LOS PIRINEOS

OCCIDENTALES PARA LA REAL ARMADA EN EL SIGLO XVIII

En el caso de los gabarreros, eran 150 los hombres que hacia 1767 trabajaban en el traslado fluvial de los materiales, contando para ello con entre 33 y 40 gabarras. Los materiales extraídos desde los montes del área atlántica de Navarra (Baztán, Cinco Villas, Basaburua o Burunda) se acumulaban en la villa de Santesteban a la que llegaban en carros o yuntas de bueyes. Desde allí, bajaban por el río. Para dicho transporte, el director firmaba una contrata, como las que en 1768 y 1769 firmó Zuaznabar para la corta, labra y conducción de la madera con Francisco Galardi y Felipe Miranda (vecinos de Hernani), Juan Esteban Olaciregui y Juan José Garbuno (vecinos de Oyarzun), desde el puente de Santesteban hasta la lonja y puerto de Fuenterrabía, donde un recibidor evaluaba la madera llegada, para enviarla al Ferrol en una embarcación mayor. Existía otra alternativa, que suponía transportar la madera hasta el puerto de Urdanibia (Irun), desde donde era trasladada en bueyes, por tierra, hasta el embarcadero de Lezo, y de allí por agua hasta Pasajes, siendo recibida por una persona designada por Zuaznabar, quien la medía y enviaba a Ferrol con un barco construido al efecto?

En el caso de los Pirineos, el asentista encargado de la corta y el transporte, contaba con diferentes cuadrillas, unas dedicadas al corte, otras al transporte por tierra, otras al acondicionamiento del río y, finalmente, otras encargadas del transporte en almadías. En el caso de Martín José de García Herreros, vecino de Pamplona, y Juan de Doray, residente en Roncesvalles, quienes firmaron en 1791 un asiento con Francisco Xavier Argaiz para durante diez años arrastrar perchas y maderas hasta el atadero de almadías, tuvieron primero que ejecutar diferentes esclusas, entablados y presas en los ríos Urbelcha y Urchuria, que daban al río Irati. Para ello se comprometieron a seguir las órdenes de los capataces de construcción Manuel Méndez y Fernando Licero (Odriozola, 2008: 845-863). Una vez realizadas las obras de acondicionamiento, debían proceder a su cuenta al corte y arrastre de las maderas entre 1792 y 1801, poniéndolas en los ataderos. Tanto para las obras hidráulicas como para el arrastre de maderas, la Marina les franquearía las cuerdas, cadenas, poleas y motones con roldanas de bronce de anteriores arrastres, debiéndolas devolver cuando acabasen y reintegrar su valor en caso de deterioro. El arrastre debía estar acabado en el mes de junio de cada año, dejando las maderas apiladas sobre polines, perchas y tosas. Para el cobro, los asentistas debían presentar dos relaciones del facultativo nombrado, una con el número de piezas y dimensiones, y la otra con las herramientas que devolviesen ${ }^{10}$. Una vez que las maderas se hallaban en el atadero, los capataces o cuadrilleros preparaban las almadías. Previamente, una vez prevista la salida de las almadías, siempre mediaba una circular en la que se pedía a todas las justicias hasta el río Ebro que tuviesen los puertos abiertos. Generalmente, los tramos eran

9. AGN, Procesos 111690.

10. AGN, CO_PS. $1^{\text {a }}$ S, Leg. 13, N. 38. 
ÁLVARO ARAGÓN-RUANO Y ÓSCAR RIEZU ELIZALDE

¿UN PROYECTO QUIMÉRICO? SUMINISTROS FORESTALES DESDE LOS PIRINEOS

OCCIDENTALES PARA LA REAL ARMADA EN EL SIGLO XVIII

de 3-4 almadías por el río Esca, hasta llegar al río Aragón, donde estos llegaban a ser de 12-14; en algunos casos se enviaron hasta 40 almadías, por ejemplo, Bastida y Barrenechea entre 1785 y 1788. La conducción de cada almadía costaba en 1786 en torno a 1.700 reales vellón, yendo en cada una siete - la almadía capitana, que guiaba al resto - o seis tripulantes - el resto - , es decir, un capataz, que cobraba 12 '5 reales, y 6 peones - la mayor parte jóvenes, de entre 25 y 30 años, que actuaban tanto componiendo madera, como conduciendo las almadías - a los que se abonaban 12 reales (en caso de quedar varada la almadía y no trabajar, 3 pesetas diarias o 5 reales fuertes, respectivamente); si bien para 1813 los jornales habían subido a 4 pesetas (16 reales) diarias. Antes de 1787 se les pagaban sus jornales diarios por el asentista y el rey, pero en la contrata que en 1785 establecieron los mencionados José Antonio de Bastida, Xabier Barrenechea, vecinos de Aoiz, junto a Gregorio Urdiroz y José Antonio de Beleret, vecinos de Lumbier, con Plácido Correa, Brigadier de la Real Armada, y Juan de Pinedo, oficial primero del Ministerio de Marina, para transportar perchas y arboladuras hasta Tortosa durante cuatro años y medio, los almadieros tomaron la almadía por un tanto para conducirla hasta Tortosa, por eso no había quién pagase jornales los días de descanso o inacción, ni se atrevía el perito a evaluar el costo de ello. El asentista controlaba la llegada de las maderas, tanto en Tortosa como en los reales arsenales, para lo que contaba con sendos comisionados o agentes: en su caso, Gambra contaba en Tortosa con José Antonio Navas y en Cartagena con Enrique Fawson o Fausson ${ }^{11}$.

Como ya hemos adelantado, en 1769 Julián de Arriaga pidió que se probara la validez de las maderas del Pirineo para el carenado de navíos y parece que la decisión fue favorable, pues en 1779 Plácido Correa, por orden del nuevo secretario de Marina, Pedro González de Castejón, viajó a los Pirineos navarros, acompañado del contramaestre Juan Bautista Donesteve, como comisionado para la elección, corte, labra y transporte de madera para la Armada. La presencia de Correa marcaba un antes y un después, pues a partir de ahora, la secretaría de Marina y la corona decidían tener una mayor presencia y control de los trabajos a realizar. Es decir, a partir de la década de los años ochenta la gestión fue directa y los funcionarios reales los encargados de supervisar todo el proceso y de establecer asientos específicos para cada una de las actividades - en los noventa se volvería a la gestión indirecta, con la firma del asiento con Gambra en 1792-. Correa estuvo entre 1779 y 1782 en los valles pirenaicos, con la orden de acondicionar el río Irati, para lo que firmó una contrata con Pedro Vicente Gambra y sus socios o acompañando a las almadías en el transporte de maderas a Tortosa. En 1785 abandonó Burunda y Echarri-Aranaz,

11. AGN, Tribunales Reales, Archivo Secreto, Tit. 4, Fajo 2, N. 53 y Tit. 33, Fajo 1, N. 2 y N. 8; Procesos 7270, 62392, 156380, 170662 y 208540; y CO_PS.1ª, Leg. 13, N. 38 y Leg. 65, N. 9; Archivo de la Casa Gambra (ACG), Sección documentación, Legajo 9 (1793). 
ÁLVARO ARAGÓN-RUANO Y ÓSCAR RIEZU ELIZALDE

¿UN PROYECTO QUIMÉRICO? SUMINISTROS FORESTALES DESDE LOS PIRINEOS

OCCIDENTALES PARA LA REAL ARMADA EN EL SIGLO XVIII

para volver al Roncal y Erro, como acabamos de ver, siendo sustituido en 1789 por Francisco Xavier Argaiz, ministro de la Cámara de Comptos. En el caso de los montes de Navarra, Álava y Guipúzcoa la estrategia fue la misma, teniendo en cuenta que en 1782 la Real Compañía de Caracas finalizaba su asiento y tres años más tarde desaparecía, quedando sus acciones amortizadas en la Real Compañía de Filipinas, lo que obligó a la corona a establecer sus propios funcionarios. Durante los años ochenta fue el ingeniero Vicente Plo el encargado de gestionar el corte y transporte de los recursos de esta zona, siendo sustituido en 1784 por Rafael Clavijo, quién además de los árboles del área navarra de Burunda, Echarri-Aranaz, Anue, Ulzama, Atez, Imoz y Basaburua, se encargó de los de la provincia de Álava. Un año más tarde Clavijo fue sustituido en el área de Burunda y Echarri por Jerónimo Tavern, bajo cuya potestad seguía Julián Vidaror, vecino de Zuriain, como asentista de maderas en el área del Bidasoa. En 1788 Tavern comisionó a Manuel Iraola para que llevase el corte de materiales en Álava y Navarra, antes de ser sustituido por José Muller, a quien encontramos entre 1790 y 1791 en los montes de Ataun y Salinas de Léniz cortando árboles para la Marina, pero también en Echarri-Aranaz. Por último, en 1796 José Muller fue sustituido por Timoteo Roch, capitán de fragata de la Real Armada, como encargado de las maderas de los montes de Navarra, Alava - donde anualmente se cortaron árboles entre 1783 y 1797, sobre todo, en la Hermandad de Villarreal - y Guipúzcoa, siendo el capataz de construcción en Uharte-Araquil Juan Tomás de Argote (Aragón, 2001: 112, 121 y 203; Iturrate, 2001-2003: 126-127) ${ }^{12}$.

A lo largo de la década de los años ochenta se intensificó la explotación de los montes del Bidasoa y de la Burunda, aunque su gestión se dividió. El corte de maderas en la zona de la Burunda, Echarri-Aranaz, Esteribar, Ulzama, Atez y Lacunza estaba a cargo del ingeniero Vicente Plo, con la participación y colaboración de Antonio Miguel Iriarte Belandía y Juan Miguel Zatarain, encargados del transporte hasta la costa. Los capataces de los cortes fueron los también guipuzcoanos Ángel Mendiguren, vecino de Elgueta, y Francisco Ignacio Galardi, vecino de Urnieta. Auxiliando a Plo se hallaba el mencionado Manuel Iraola, contramaestre de construcción. Por su parte, en los montes del Bidasoa era Julián Vidaror el encargado de llevar a cabo la conducción de las maderas en el entorno del río Bidasoa, para lo que firmó tres asientos, en los años 1782 - en el que también recibió permiso para cortar hayas en Irati y transportarlas a Santesteban utilizando las infraestructuras construidas por Gambra entre 1779 y $1781-, 1785$ y 1788, y tenía a su cargo dos comisionados o asentistas de maderas, encargados del corte y conducción de las mismas: Martin de Michelena y Goyeneche, y José Salaberria. Durante el mandato de Rafael Clavijo

12. AGN, Procesos 7269 (I y II), 93081,93858 y 93982; Tribunales Reales, Archivo Secreto, Tit. 4, Fajo 2, N. 35, 36, 46, 50, 53, 57 y 64, Fajo 3, N. 8 y 75; y Tit. 33, Fajo 1, N. 2, 3, 4 y 5; VR_DOCUMENTOS, Leg. 47, N. 3; Leg. 70, N. 24, 28 y 31; y Leg. 71, N. 17. 
ÁLVARO ARAGÓN-RUANO Y ÓSCAR RIEZU ELIZALDE

¿UN PROYECTO QUIMÉRICO? SUMINISTROS FORESTALES DESDE LOS PIRINEOS

OCCIDENTALES PARA LA REAL ARMADA EN EL SIGLO XVIII

continuó como su subalterno el contramaestre Manuel Iraola, a cuyo cargo tenía dos capataces guipuzcoanos, concretamente de Urnieta: el ya mencionado Galardi, encargado de los cortes en Echarri-Aranaz, y Francisco Aizpurua en la Burunda ${ }^{13}$.

En 1784 hallamos nuevamente a Rafael Clavijo, ingeniero ordinario de Marina, pero encargado de las maderas en los montes del Bidasoa y marcando árboles en Álava. En esta ocasión, en el caso del Bidasoa, Clavijo estaba al cargo de la obtención de madera de haya para transportarla a Cádiz, a fin de construir, por un lado, un dique seco, y por otro, remos y duelas para fabricar barricas en las que transportar clavazón para la construcción naval. Entre 1783 y 1791 fue Ignacio Lasarte, tonelero de San Sebastián, quien proveyó de todas las barricas necesarias para el transporte de clavazón a Ferrol, Cádiz y Cartagena; a su muerte continuó con el asiento su viuda. Las maderas de haya fueron bajadas por el río Bidasoa en gabarras y cargadas en Pasajes en una fragata real y cuatro embarcaciones de comercio, fletadas por el rey ${ }^{14}$.

La infraestructura en torno a los montes del Bidasoa siguió activa en el siglo XIX y dichos montes siguieron mandado madera al Ferrol en la década de los años veinte. En 1824, por ejemplo, Antonio Orfila Rotger y Manuel Ciaran firmaron sendas contratas con los directores del departamento del Ferrol para la provisión de maderas para el carenado de barcos ${ }^{15}$. Por su parte, la explotación de los montes del macizo pirenaico continuó a lo largo del siglo XIX. En 1806 una Real Orden establecía la protección de los árboles de los montes pirenaicos para la Real Armada. A pesar de que la Guerra de la Independencia provocó numerosas destrucciones en estos montes, la extracción de maderas desde Irati continuó en la década de los años veinte. En el año 1824, nostálgico de los grandes tiempos de la extracción de maderas para la Armada y tratando de revitalizar la economía local, Gabriel Antonio Mancho, vecino de Ochagavía, presentó un plan para rehabilitar dicha actividad, requiriendo sin éxito financiación al Real Erario. Dos años después, una comisión recorrió los Pirineos en Navarra y Aragón para evaluar qué arboles eran factibles de ser utilizados para la Armada. No obstante, junto a la Marina surgieron otras competidoras, como la extracción a Francia de remos y madera o la elaboración de ceniza para la fabricación de cristales; en ese sentido, el suizo Marco Andrés Joër estableció una contrata por diez años, entre 1826 y 1836. Tras el período de guerras vivido (Guerra de la Convención, Guerra de la Independencia, Trienio Liberal e invasión de los Cien Mil Hijos de San Luis), los valles pirenaicos se hallaban exhaustos, por lo que se vieron obligados a cobrar a la Armada Real los árboles extraídos - en 1808, 1816

13. AGN, Procesos 193045 (I y II); Tribunales Reales, Archivo Secreto, Tit. 4, Fajo 2, N. 46 y Tit. 33, Fajo 1, N. 4.

14. AGN, 82223 y Tribunales Reales, Archivo Secreto, Tit. 4, Fajo 2, N. 46; ATHA, legajo 46, ff. 149v - 150r, 153v - 154r, 172r y v, y legajo 47, ff. 3r - 4v.

15. AGN, Procesos 221860. 
y 1818 se condenó a la Real Hacienda a pagar el importe de los pinabetes y demás árboles cortados en Irati- y a buscar nuevas fuentes de financiación a través de sus bosques y montes. Por último, todavía en 1841 se extrajeron árboles en los montes del valle de Salazar para la construcción de buques ${ }^{16}$.

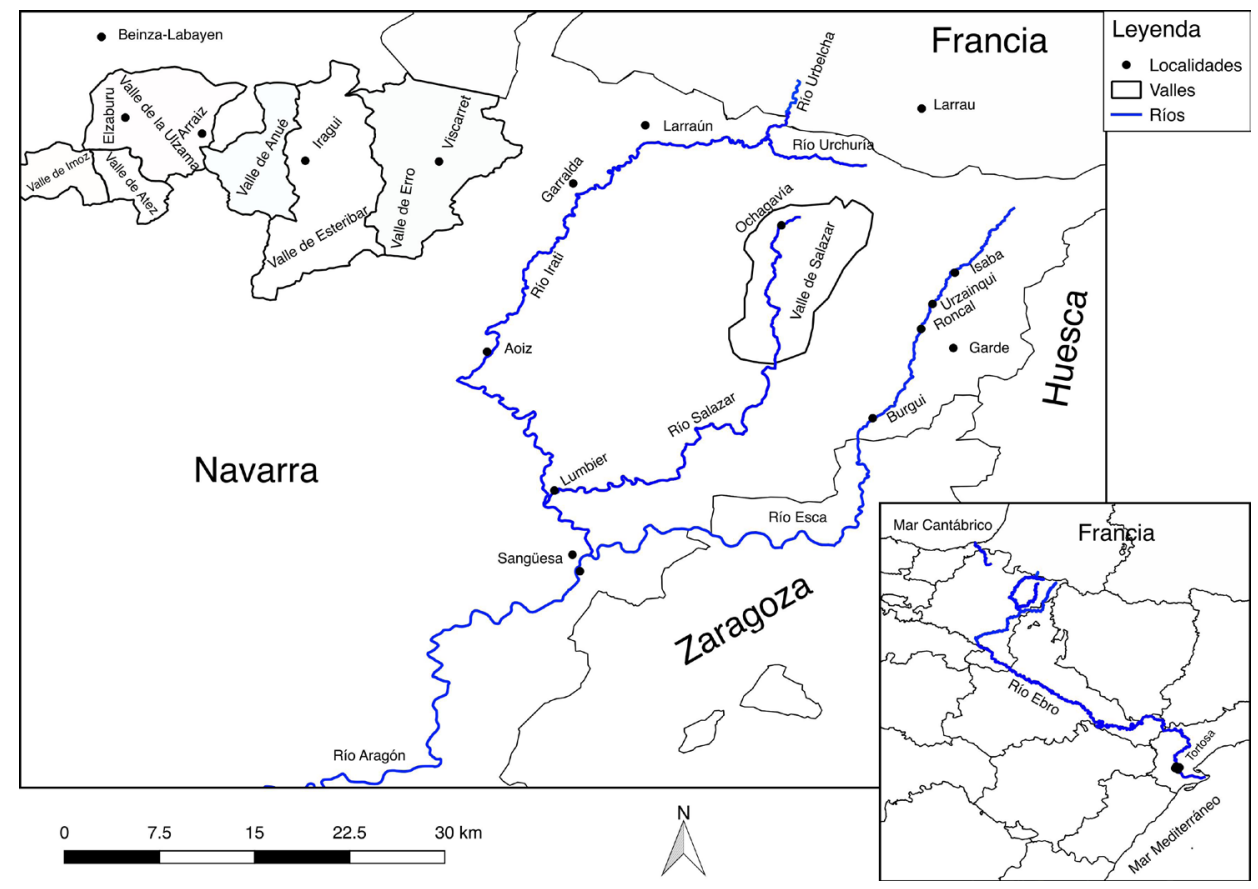

Mapa 2. Extracción de maderas desde la Navarra oriental (autor: Óscar Riezu Elizalde).

Otra de las grandes actividades relacionadas con la Marina y la Armada real fue la extracción de madera de haya y la fabricación de remos. Para la década de los años veinte del siglo XVIII ya encontramos a comerciantes y fabricantes de remos de San Sebastián en los montes de Ataun (Guipúzcoa), Ergoyena y EcharriAranaz (Navarra), y entre 1680 y 1727 de Bilbao en los montes de Gorbea y Altube (Álava) (Aragón, 2001: 111; Iturrate, 2001-2003: 118-126) ${ }^{17}$. Las grandes dinastías de empresarios del sector serán a lo largo del siglo XVIII los Orella o Elizalde de

16. AGN, Montes, Legajo 2, Carpeta 34 y 39; VR_DOCUMENTOS, Leg. 16, N. 25; Archivo de la Junta del Valle de Aezkoa, CAJA 027, 9 y CAJA 041, 12.

17. AGN, Procesos 33210. 
ÁLVARO ARAGÓN-RUANO Y ÓSCAR RIEZU ELIZALDE

¿UN PROYECTO QUIMÉRICO? SUMINISTROS FORESTALES DESDE LOS PIRINEOS

OCCIDENTALES PARA LA REAL ARMADA EN EL SIGLO XVIII

San Sebastián que ya aparecen para 1743 o los Garro y Oronoz de Bilbao para 1755, abasteciendo a la Real Compañía de Caracas, a los Paquebotes de Correos, al astillero de Guarnizo o vendiendo sus remos en Asturias y Galicia. En ambos casos, nos encontramos con personajes de origen navarro, que se han trasladado a las provincias costeras, a pesar de lo cual mantienen vínculos con su patria, mostrando una importante endogamia familiar y geográfica, pues familiares y compatriotas participan en sus negocios y actúan como agentes o comisionados, además de realizar las labores de tala de árboles y confección de los remos. La estructura de estas empresas particulares era algo diferente a las descritas hasta ahora. Dichos particulares firmaban contratas con la Real Compañía de Caracas o con la propia Marina, directamente o a través de terceros; es decir, la fabricación de remos no era realizada directamente por la Armada o por la Real Compañía de Caracas, sino que se subcontrataba. Orella firmaba un contrato con Claessens o Zuaznabar, directores de la Real Compañía de Caracas, por el que se comprometía a aportar un número determinado de remos de diferentes calidades en una fecha concreta a pie de puerto, en San Sebastián o Pasajes. A tal fin, Orella debía firmar una contrata con las villas dueñas de los montes hayedos desde los que se iban a extraer los remos, para lo cual daba un poder a un allegado o agente suyo, por ejemplo, en 1756 a Juan Azpiroz, vecino de Huici, estando a cargo de las labores José Iriarte, vecino de Areso ${ }^{18}$. Los Garro u Oronoz de Bilbao, originarios de Beruete, se avenían con el administrador principal de la Estafeta de Bilbao y de la construcción de Paquebotes de Correos Marítimos, fabricados de cuenta de la Real Hacienda en el astillero de Zorroza, en la anteiglesia de Abando, o con Manuel de Zubiría, vecino de Bilbao, asentista de la Real Fábrica de Navíos en el Real Astillero de Guarnizo. A su vez, Miguel Oronoz daba su poder a Martín Elzaburu - natural de Beruete, maestro remero en San Sebastián - , quien era el encargado de viajar a la villa poseedora de las hayas y firmar una contrata, en la que se concretaba dónde se cortaría las hayas y a qué precio. Una vez cortados, dichos remos eran transportados en carros - orgas, en euskera - hasta Santesteban, donde eran embarcados en gabarras y conducidos a Fuenterrabía, cuyo Ayuntamiento debía dar licencia para poder ser llevados hasta el cargadero y ser embarcados en una pinaza que los llevase a San Sebastián o Bilbao; el transporte desde San Sebastián a Bilbao corría, por supuesto, a cargo del empresario contratante ${ }^{19}$.

En ocasiones, Garro establecía convenio con un intermediario, normalmente un comerciante de Bilbao, como en 1768, Tomás de Sant Aulari, vecino de Bilbao, comisionado por Pedro de Ordeñana, Caballero de la Real Orden de Santiago e

18. AGN, Procesos 33210, 49830 y 49980.

19. Archivo Histórico Foral de Bizkaia (AHFB), Gobierno y asuntos eclesiásticos, AJ03253/014 y AJ03297/013. 
ÁLVARO ARAGÓN-RUANO Y ÓSCAR RIEZU ELIZALDE

¿UN PROYECTO QUIMÉRICO? SUMINISTROS FORESTALES DESDE LOS PIRINEOS

OCCIDENTALES PARA LA REAL ARMADA EN EL SIGLO XVIII

Intendente General del Departamento de Ferrol, para la construcción de remos para lanchones y lanchas. A su vez Garro firmaba una escritura de convenio, por medio de un intermediario, con la villa en cuyos montes se pretendía hacer los remos (Cinco Villas, Basaburúa o Larráun). En 1784 ese intermediario fue Juan José Larrea, residente en Beruete, en 1787 el poderhabiente fue el sobrino de Garro, Martín José Garro, residente en Aldaz, cargo que repitió, junto a Miguel Francisco Zabalo, vecino de Beruete, en 1796. Garro contrataba a los trabajadores y maestros remeros, con los que firmaba un convenio en función de las labores a realizar, y estos creaban sus propias cuadrillas o lanteguis - compuestas por dos o tres hacheros, un cepillador y un muchacho (Iturrate, 2001-2003: 123-124) - ${ }^{20}$, estableciendo convenios individualizados. Por ejemplo, en 1785 Martín José Garro, firmó un convenio con Martín José Urriza, vecino de Arraras, para el cepillado de 116 orgas de remos, quien a su vez hizo lo propio con Pedro Garro, Juan Esteban Gaztearena, ambos vecinos de Arraras, Joaquín Arregui, residente en Igoa, pariente en cuarto grado de Martín José Urriza, y Juan Esteban Irurzun, residente en Aizaroz; por tanto Urriza contrató gentes de su confianza y entorno geográfico y familiar ${ }^{21}$. Más aún, en 1790, Pedro Martín Garro fue contratado como cepillador de remos por sus primos Joaquín y Martín José Garro, todos vecinos de Beruete, aunque el último residente en San Sebastián. Para la compra en 1791 de hayas en Beinza-Labayen, fue nuevamente el sobrino quien contrató a Juan Antonio Marticorena, vecino de dicha villa, el cual se comprometió a elegir vecinos de la propia villa para el corte y transporte y se ajustó extrajudicialmente con Garro para la entrega de los remos que conduciría hasta San Sebastián y de allí a Zorroza. El propio Martín José de Garro, había actuado años atrás, en la década de los cincuenta del siglo XVIII, como maestro remero en los montes de la frontera entre España y Francia, concretamente en Cisa y Orbaiceta, con muchos compatriotas, naturales de Beruete, Aldaz o Huici, junto con una treintena de trabajadores del valle de Larrau (Francia), todos ellos bajo el mando de Miguel Echeverria, natural de Urruña (Labort); los remos eran llevados en carros hasta San Juan de Luz y de allí por el agua hasta Bayona. En el caso del Bidasoa, como ocurría con la tablazón, de existir la posibilidad, las orgas o carretadas de remos se transportaban en carros, con bueyes, o a través del río Bidasoa, para lo cual se enviaban a Santesteban y desde allí se bajaban por el río, para finalmente ser transportadas en barco a Bilbao ${ }^{22}$.

20. AGN, Procesos 93081.

21. AHFB, Seguridad pública, guerras y servicio militar, AQ00865/054.

22. AGN, Procesos 21341, 21782, 22440, 22625, 23417, 93543, 111550 y 170788. 


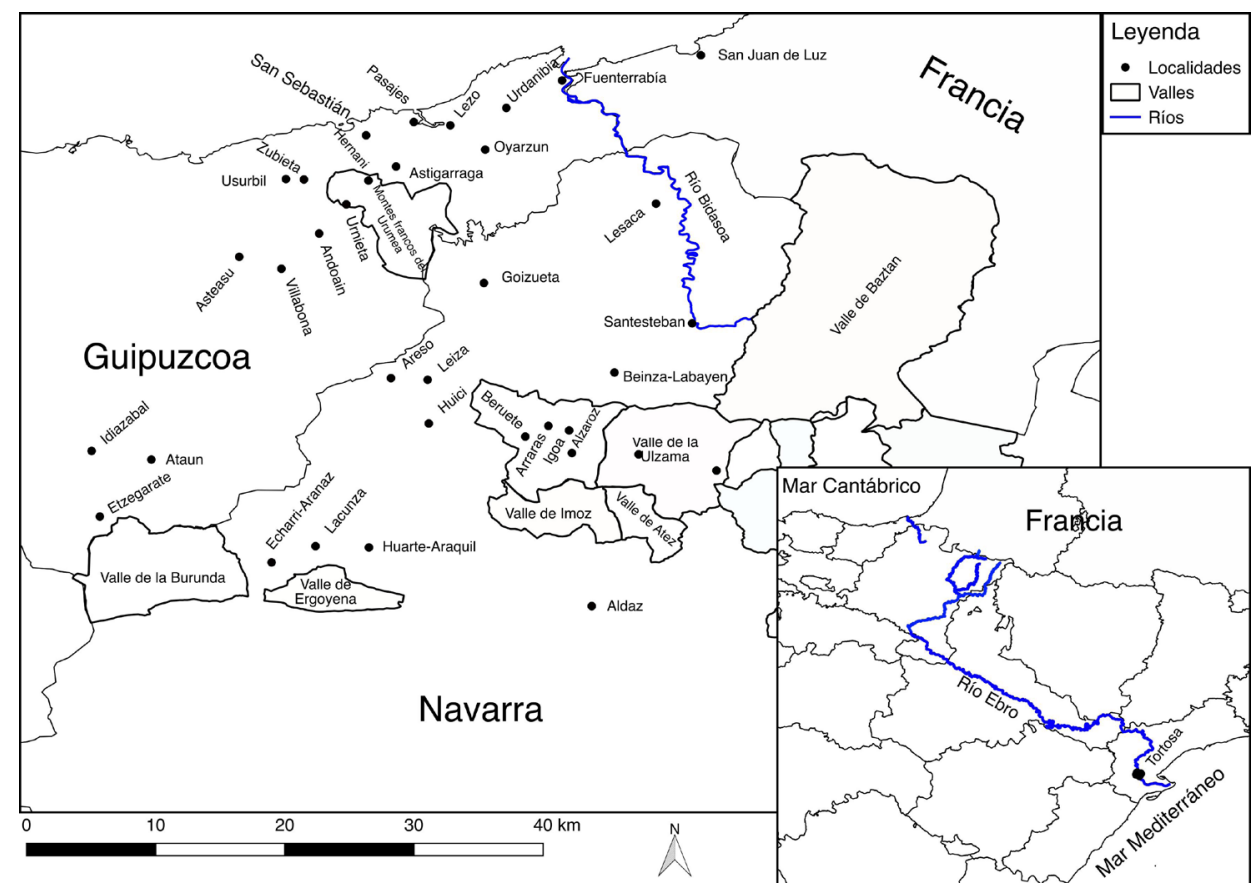

MaPa 3. Área de extracción de maderas desde la Navarra occidental y Guipúzcoa (autor: Óscar Riezu Elizalde).

\section{OBSTÁCULOS Y DIFICULTADES A LAS QUE HUBO DE HACER FRENTE LA EXPLOTACIÓN DE LOS RECURSOS PIRENAICOS}

Los obstáculos con los que tropezaron quienes se hicieron cargo de tamaña empresa fueron importantes, ralentizando y dificultando la actividad y elevando los costos, gastos y desembolsos de dinero en extremo (Aragón, 2017: 45-52).

Los asentistas reclamaron la exclusividad del uso y explotación de los montes y se negaron a compartirlos con las comunidades o con otros compradores, sin su permiso. En 1703 Goyeneche alegaba tener la exclusividad en el corte y se opuso a la venta de 600 árboles que Burgui había concedido a Juan Baines, vecino de Zaragoza $^{23}$. La explotación de los montes de los Pirineos por parte de los asentistas distorsionó la actividad de las comunidades locales, provocando inconvenientes en

23. AGN, Procesos 4986 y 5012. 
ÁLVARO ARAGÓN-RUANO Y ÓSCAR RIEZU ELIZALDE

¿UN PROYECTO QUIMÉRICO? SUMINISTROS FORESTALES DESDE LOS PIRINEOS

OCCIDENTALES PARA LA REAL ARMADA EN EL SIGLO XVIII

las principales actividades productivas. Por ejemplo, en 1767, los vecinos de Goizueta que contaban con privilegios de pasto en los montes de Anizlarrea, propiedad de la Real Colegiata de Roncesvalles, se quejaban de que la extracción de árboles para la Marina había reducido el pasto disponible y cada vez eran menos las cabezas que se podían mantener e introducir, mientras que la vecina villa de Lesaca denunciaba que dichos cortes perjudicaban a sus ferrerías, que se habían visto obligadas a ir cada vez más lejos a buscar el carbón vegetal, provocando el cierre de algunas de ellas ${ }^{24}$.

En 1780 y 1781 - habiendo visto el Reino de Navarra confirmada su privativa jurisdicción en materia de montes, en lo respectivo a lo económico y político, quedando lo contencioso en manos de un Juez de Montes, que finalmente sería navarro - las Cortes de Navarra establecieron ciertas limitaciones, por los excesos que se habían cometido por parte de los asentistas, tratando de proteger a las comunidades locales, y obligaron a que primero mediara la sobrecarta del Consejo Real de Navarra y no se procediese al corte hasta la evaluación - que debía ser realizada por dos peritos, elegidos por cada parte-y pago de los árboles - lo mismo ocurrió en Aragón-. Hasta la fecha, la Real Compañía de Caracas primero cortaba las maderas, luego las partes las evaluaban y el pago se hacía en depósito en Pamplona o en San Sebastián, a donde debían acudir las localidades a cobrar. Pero a partir de entonces y hasta los años noventa, las localidades navarras paralizaron el corte hasta que mediase sobrecarta del Consejo y se abonasen las cantidades adeudadas - algo similar ocurrió en el caso de los montes del Departamento de Cádiz, donde los dueños de los árboles exigían que se les pagase antes del corte-. Julián Vidaror, por ejemplo, a pesar de que la Real Orden de 1789 ordenaba que se eligiesen peritos para la tasación de árboles en caso de discordia, vio cómo la parte contraria no elegía a su perito y las maderas permanecían en el monte, con el consiguiente deterioro. El Real Consejo de Navarra respondió que no se podía dar orden sin su sobrecarta. Debido al retraso, el rey decidió nombrar al ingeniero y capitán de fragata José Muller para proceder a una nueva marcación (Aragón, 2019: 155; Quintero, 2004) ${ }^{25}$.

Relacionado con el peritaje de los bosques, uno de los grandes caballos de batalla entre la Marina y las villas y comunidades rurales fue el desencuentro en torno al precio de los árboles. Tanto en el caso de Guipúzcoa como de Navarra, las villas querían sacar el máximo beneficio posible y que se pagase a precio de mercado, mientras que los asentistas buscaban abaratar los costos. Las villas se opusieron a la labra y entrega de las maderas derribadas, mientras no fuesen pagadas, mientras que los asentistas alegaban que las piezas no podían ser abonadas hasta asegurarse de cuáles eran útiles y cuáles no. La fórmula seguida para solucionar estos problemas

24. AGN, Procesos 155563 y Tribunales Reales, Archivo Secreto, Tit. 4, Fajo 2, N. 15.

25. AGN, VR_DOCUMENTOS, Leg. 70, N. 24 y Reales tribunales, Archivo Secreto, Tit. 4, Fajo 3, N. 8. 
ÁLVARO ARAGÓN-RUANO Y ÓSCAR RIEZU ELIZALDE

¿UN PROYECTO QUIMÉRICO? SUMINISTROS FORESTALES DESDE LOS PIRINEOS

OCCIDENTALES PARA LA REAL ARMADA EN EL SIGLO XVIII

fue el ajuste entre ambas partes, por medio de la elección de peritos y, en caso de falta de acuerdo, la de un tercero. Además, una de las mayores controversias surgió en torno a la unidad de medida utilizada, por pieza o árbol - como prefería la Marina, por resultarle más económico- o por codos, y en este caso, en torno a la utilización de codos cúbicos o de codos regulares: las autoridades de Marina estaban acostumbradas a utilizar codos cúbicos, mientras que en Guipúzcoa era más habitual el uso de codos regulares, algo más pequeños; la corona, en una decisión salomónica, estableció finalmente un precio intermedio. En el caso de Navarra, las desavenencias surgieron en torno al uso de codos navarros o de codos castellanos, estos mayores que los primeros y utilizados habitualmente por la Marina, lo que provocó problemas en la medición y el costo de las piezas (Aragón, 2001: 158-160 y 2017: 46-47) ${ }^{26}$.

Uno de los grandes obstáculos al que tuvieron que enfrentarse los asentistas fue el derivado de una intrincada orografía y la falta de infraestructuras viarias adecuadas para la extracción de los recursos. La vía habitual de extracción de las maderas en los valles del Pirineo navarro venían siendo los ríos, por lo que los bosques más explotados eran los más cercanos a las vías fluviales. Pero los árboles más grandes y codiciados para su uso como mástiles se hallaban lejos de las principales vías fluviales y se debían sortear gargantas y barrancos inaccesibles, en las partes altas de los cauces de los ríos, donde realmente eran regatas que contaban con escaso caudal. Por tanto, una de las primeras dificultades que debieron salvar fue el acondicionamiento de estos cursos altos de los ríos, para poder transportar los troncos hasta los cursos principales. Ya en 1696 Antonio Oset, quien había firmado escritura para conducir 1.700 maderos, para lo cual estableció un año antes un convenio con la villa de Isaba para su extracción durante 10 años desde el pinar de Ardibide Soroa, tuvo que gastar 2.000 reales de a ocho para limpiar y acondicionar el río ${ }^{27}$. Normalmente, la firma de un convenio con alguna de las villas que jalonaban el recorrido del río en el curso alto del Irati o del Esca, obligaba a los asentistas, quienes pretendían también el uso exclusivo de los ríos, a respetar los usos y costumbres de las comunidades locales. Es decir, a pesar de que quien tenía preferencia de uso del río era el asentista, los miembros de las comunidades locales tenían derecho a extraer maderas, siempre y cuando contasen con la licencia y permiso de aquel. Esta cuestión generó numerosas denuncias, tanto en el caso del asiento de Juan de Goyeneche y José Vidarte, como en el posterior de Pedro Vicente Gambra. Así en 1702 Vidarte acusó a Bernardo Ros de bajar madera utilizando su esclusa, sin su permiso, mientras que la parte acusada, con el apoyo de la villa de Isaba, alegaba que

26. AGN, Procesos 5164; VR_DOCUMENTOS, Leg. 70, N. 24; Tribunales Reales, Archivo Secreto, Tit. 4, Fajo 2, N. 50 y Tit. 33, Fajo 1, N. 1.

27. AGN, Procesos 60193. 
ÁLVARO ARAGÓN-RUANO Y ÓSCAR RIEZU ELIZALDE

¿UN PROYECTO QUIMÉRICO? SUMINISTROS FORESTALES DESDE LOS PIRINEOS

OCCIDENTALES PARA LA REAL ARMADA EN EL SIGLO XVIII

el río Esca era propio y privativo de la villa y, por tanto, su uso era libre; de hecho, los habitantes de las localidades pirenaicas lo habían utilizado siempre, incluso para extraer maderas, sin problemas ${ }^{28}$.

No solo eso, la cuestión del pago de tasas por el paso de las almadías por los referidos ríos hasta su llegada al río Aragón y, desde aquí, al Ebro fue endémica. A pesar de que en el asiento firmado por Goyeneche con la Corona se especificaba claramente que estaba exento del pago de derechos, las localidades por las que pasaban sus almadías le exigieron su abono. Goyeneche hubo de reclamar a la corona, que le concedió una sobrecarta en 1700, confirmando la mencionada exención ${ }^{29}$. Más aún, dos años más tarde, vecinos de Isaba y Roncal detuvieron a los almadieros que trabajaban para Goyeneche y Vidarte, acusándoles de cortar las ligaduras, ramas de avellano y otros árboles o arbustos, sin permiso de los respectivos concejos, con los que unían los troncos para confeccionar los diferentes tramos de almadía. Así mismo, encarcelaron a los operarios que se hallaban trabajando en la esclusa del río Esca a la altura de Idoya (Isaba) ${ }^{30}$. El problema se reprodujo en tiempos de Pedro Vicente Gambra, acusado de fraude, al no abonar los peajes. Gambra alegaba que el asiento que él estableció para proveer de maderas al arsenal de Cartagena le garantizaba la exención, sin embargo, en 1793 las localidades solicitantes manifestaban que una Real Orden establecida ese mismo año obligaba a todos los asentistas a pagar tasas, a lo que Gambra respondió que su asiento era anterior a la citada orden, concretamente, del 30 de noviembre de 1792, por lo que debía respetársele. Finalmente, Gambra fue eximido, pues la Real Hacienda se hizo cargo del pago de los derechos hasta 1793, sin embargo, fue obligado a pagar 1.430 reales, en concepto de peajes correspondientes al período 1793-1795 .

Otro de los problemas más habituales contra los que tuvieron que lidiar los asentistas en el ámbito de los ríos fue el de los desperfectos y daños causados por las maderas en su transporte. A los habituales choques de troncos o destrozos generados en los puertos y presas de los molinos que jalonaban los ríos de paso, se deben unir las catástrofes naturales generadas coyunturalmente por las avenidas de los ríos. El 7 de diciembre de 1702 una avenida del río Esca, la mayor en 50 años, al decir de los testigos, provocó numerosos daños en el molino de Garde, cuyos vecinos se vieron obligados a moler sus cereales en el molino de Roncal. Garde alegaba que las maderas sueltas que se hallaban en las márgenes de los riachuelos a la espera de componer las almadías, habían sido arrastradas por la avenida y habían provocado grandes daños. Sin embargo, Goyeneche y Vidarte fueron absueltos,

28. AGN, Procesos 4968.

29. AGN, Procesos 5164, 91378 y 190449.

30. AGN, Procesos 91374.

31. AGN, CO_PS.1 ${ }^{a}$ S. Leg. 10, N. 30. 
ÁLVARO ARAGÓN-RUANO Y ÓSCAR RIEZU ELIZALDE

¿UN PROYECTO QUIMÉRICO? SUMINISTROS FORESTALES DESDE LOS PIRINEOS

OCCIDENTALES PARA LA REAL ARMADA EN EL SIGLO XVIII

por considerarse que los daños no eran achacables a dichos maderos y se hubiesen producido de cualquier manera, a consecuencia de la extrema fuerza del agua. En una última intentona, Garde se quejaba de que la rotura de una roca para la construcción de una esclusa, había restado un impedimento natural al río y facilitado la acción de las avenidas. En su caso, Correa y Pedro Vicente Gambra tuvieron que hacer frente entre 1779 y 1802 a casi una treintena de pleitos elevados por diferentes villas del trayecto de las almadías, en los ríos Esca, Aragón y Ebro, acusándoles de diferentes destrozos en sus presas, pesqueras y molinos ${ }^{32}$. Similares situaciones se vivieron en la Sierra de Segura, en lo relativo a la apertura de presas y portillos para el paso de las maderas. En 1785 el ingeniero Manuel Bernia intentó hacer el río Segura navegable y presentó un ambicioso proyecto que se llevó a efecto entre 1784 y 1793, permitiendo el abastecimiento maderero desde la provincia marítima de Segura hasta Cartagena, a través de la flotación de maderas por el río Segura. El trayecto era ciertamente prolongado, pues a diferencia de lo que ocurría hasta Tortosa, en este caso llegaba a ser de hasta ocho meses, es decir, el doble. Además, debido a lo intrincado del río, se tuvieron que reducir las dimensiones de las piezas, para adecuarlas al curso del río Segura. Esto tuvo importantes repercusiones en la labor constructiva, pues obligó a utilizar la técnica del ensamblaje, algo que siempre se intentaba evitar a toda costa (López, 2018: 127-168).

El transporte de los troncos y almadías por los cursos amplios de los ríos no era un «mar de rosas» y los accidentes eran habituales, más allá de los períodos de avenidas o crecidas del río. También era un problema el escaso cauce de los ríos, sobre todo durante los periodos de estiaje, y los problemas y quejas fueron numerosos en los casos del río Ebro o Bidasoa. Por ejemplo, en el río Ebro se produjeron numerosos hundimientos de los barcos que transportaban madera, cuando chocaban contra ramas, rocas o alguna infraestructura hidráulica, o retrasos en la salida y navegación de los barcos hasta que las condiciones fuesen adecuadas. De hecho, los grandes ríos de Navarra o Guipúzcoa estaban jalonados por presas, pesqueras y nasas que dificultaban el paso de las almadías y gabarras. En numerosas ocasiones, el paso por una de estas infraestructuras retrasaba el transporte, y las almadías se veían obligadas a parar, ser desmontadas y nuevamente reconstruidas, con el consiguiente aumento de gastos, porque además de abonar los jornales a los almadieros, a pesar de la inactividad, se debían pagar los de aquellos que se encargaban de desmontarlas y volverlas a montar ${ }^{33}$.

En ocasiones, donde la orografía lo permitía, el transporte de los troncos se hacía por tierra, para lo que los asentistas estaban obligados a arreglar los caminos

32. AGN, Procesos 7270 y 190449; Tribunales Reales, Archivo Secreto, Tit. 4, Fajo 2, N. 35.

33. AGN, Procesos 112355; Tribunales Reales, Archivo Secreto, Tit. Fajo 2 N. 53 y Tit. 33, Fajo 1, N. 2 y N. 5. 
ÁLVARO ARAGÓN-RUANO Y ÓSCAR RIEZU ELIZALDE

¿UN PROYECTO QUIMÉRICO? SUMINISTROS FORESTALES DESDE LOS PIRINEOS

OCCIDENTALES PARA LA REAL ARMADA EN EL SIGLO XVIII

y costear los gastos derivados. El convenio firmado en 1705 con Roncal, obligaba a Goyeneche y Vidarte a arreglar los caminos y los puentes por los que hubiesen de pasar sus oficiales con los troncos extraídos. En 1769 los concejos de las Cinco Villas de Navarra o Baztán hicieron llegar sus quejas y años más tarde, las autoridades guipuzcoanas, por los desperfectos provocados en los caminos reales, a pesar de que en los asientos siempre se especificaba que el transporte de las maderas debía realizarse por caminos carretiles, como ya había establecido en Vizcaya su corregidor desde $1723^{34}$. Una Real Cédula de 1772 obligaba en Guipúzcoa a transportar los maderos sobre un carro o sobre cuatro ruedas en caso de ser de gran longitud, pero ante las reiteradas protestas elevadas por villas como Placencia y Elgóibar, por los daños que las llantas estrechas provocaban, la Provincia ordenó el uso de llantas anchas. Finalmente, en 1789 se emitió una serie de ordenanzas regulando el buen uso del Camino Real de Coches y el cobro de peajes a los asentistas, sin embargo, todavía en 1791 las Juntas Generales seguían debatiendo la necesidad de evitar y hacer pagar los daños que los asentistas causaban en los caminos de la provincia (Aragón, 2001: 115) 35 .

En este ámbito del transporte por tierra, los mencionados asentistas que actuaban en Navarra para la Real Compañía de Caracas tuvieron muchísimos problemas desde 1769 con las comunidades locales, poseedoras de los medios de tiro necesarios para el transporte de las maderas, y en muchos casos optaron por la coerción contra ellas y sus boyerizos, que preferían dedicarse al comercio, actividad mejor pagada. Para ello establecían una matrícula de las yuntas de bueyes que existían en cada localidad y valle, para luego solicitar su participación. No obstante, eran muchos los que se ausentaban, a pesar de las amenazas, por lo que los asentistas se vieron finalmente obligados a pedir que a aquellos que no aportasen sus bueyes se les cobrase 1 real diario por cada yunta de bueyes, para de esa manera financiar el mantenimiento de la caballería que llevaban consigo aquellos que si participaban, en la que transportaban sus vituallas, vestimenta y demás aperos. La petición generó, por supuesto, el rechazo y oposición de muchos pueblos. De hecho, los boyerizos se habían venido quejando de las cantidades que se les ofrecían (5-6 reales diarios) y exigían que se les añadiera al menos un real para el mantenimiento de dicha caballería. Lo cierto es que los jornales que cobraban los boyerizos en el transporte de otros productos comerciales eran superiores - en torno a los 8-9 reales diarios - y pedían que se les equiparasen. Los problemas arreciaban durante el invierno, cuando faltaba el alimento de los animales y era más difícil su obtención ${ }^{36}$. La situación en Guipúzcoa

34. AGN, Procesos 5164; Tribunales Reales, Archivo Secreto, Tit. 4, Fajo 2, N. 17 y Tit. 33, Fajo 1, N. 1.

35. AHFB, Bilbao Antigua 0253/001/010.

36. AGN, VR_DOCUMENTOS, Leg. 47, N.3 y Tribunales Reales, Archivo Secreto, Tit. 33, Fajo 1, N. 1. 
ÁLVARO ARAGÓN-RUANO Y ÓSCAR RIEZU ELIZALDE

¿UN PROYECTO QUIMÉRICO? SUMINISTROS FORESTALES DESDE LOS PIRINEOS

OCCIDENTALES PARA LA REAL ARMADA EN EL SIGLO XVIII

o Vizcaya era la misma y en 1782 los boyerizos contratados por Iriarte Belandía y Zatarain, desde Idiazábal hasta Astigarraga, protagonizaron un paro y se negaron a transportar la madera, a pesar de la oferta de dos reales más por codo transportado desde el puerto de Yarza o Beasain y un maravedí por codo desde el Camino Real, pues dicha subida no compensaba lo que ganaban en otras actividades ni el perjuicio que, al parecer, sufrían los animales (Aragón, 2001: 125) ${ }^{37}$.

Este tipo de problemas no se produjo únicamente en los Pirineos y fueron similares en otros entornos, como la Sierra de Segura o en el Departamento de Cádiz. En el primer caso, se produjeron numerosos conflictos con los carreteros y hacheros, sobre todo en torno a los precios y sueldos pagados. Los árboles llegaban a ser de 16 metros de largo y medio metro de ancho, por lo que no se podían transportar por flotación hasta los ríos Guadalimar y Guadalquivir. En el segundo caso, los problemas se centraron en el transporte, por el estado de los caminos, las dimensiones de las piezas y la falta de estímulos de los carreteros. Estos últimos, pedían más dinero para el alimento de los animales de tiro, lo que retrasó la llegada de las maderas al astillero, y se quejaban de que el transporte de pino salgareño era más complicado que el del pino rodeno, que habían extraído hasta la fecha para la Fábrica de Tabaco de Sevilla: era más pesado, las piezas más largas, tenían que subir a zonas más intricadas y con más pendiente, y, finalmente, no contaban con zonas adecuadas en las que dar de comer a los bueyes (López, 2009 y 2017; Quintero, 2004).

Julián Vidaror, comisionado para la conducción de maderas, tuvo que afrontar una situación similar en 1779. En este caso, lo intricado de los lugares de extracción de los robles perjudicaba a los boyerizos y sus animales, quienes se quejaban de que tras dicha actividad sus bueyes no eran capaces de trabajar en la agricultura, debido a la fatiga. Ante esta situación, muchos de ellos se negaban a cargar grandes pesos, por lo que cobraban jornales menores, lo cual volvía a provocar recelos entre los boyerizos, que obtenían mejores ingresos en el comercio. La clave estaba en que se obligaba a los bueyes a subir y bajar grandes pendientes, hasta donde se hallaban los troncos o tablones que debían transportar, lo cual fatigaba en exceso a unos animales poco acostumbrados a ese tipo de trabajos y más habituados a las labores agrícolas. Las peticiones para que se utilizasen bueyes adecuados para labores tan duras, es decir, bueyes acostumbrados al transporte de cargas pesadas y no bueyes jóvenes o utilizados únicamente en labores agrícolas, fueron reiteradas, a pesar de lo cual los problemas continuaron, e incluso se produjo la muerte de algún animal. Por otro lado, el mal estado de los caminos impedía en muchas ocasiones el tránsito de carros, obligando a los asentistas a utilizar acémilas para el transporte, lo que elevaba los costes exponencialmente; por ejemplo el asentista de la Real Compañía de Caracas se quejaba en 1779 de haber tenido 18.000 pesos de pérdida por esa causa. Fue tal

\section{AHFB, JCR2625/003.}


ÁLVARO ARAGÓN-RUANO Y ÓSCAR RIEZU ELIZALDE ¿UN PROYECTO QUIMÉRICO? SUMINISTROS FORESTALES DESDE LOS PIRINEOS OCCIDENTALES PARA LA REAL ARMADA EN EL SIGLO XVIII

el conflicto en torno a las yuntas de bueyes y al absentismo de los boyerizos de los valles atlánticos navarros, que en 1767 Zuaznabar decidió comprar ocho pares de bueyes por cuenta de la Real Hacienda, para cuya manutención eran preciso arrendar unas dos yugadas de tierra para hacer hierba o algún grano, o comprar los forrajes, que en tiempo de dificultades eran importados desde Francia, y en 1786 Julián Vidaror, para poder transportar los 10.000 codos anuales que se había comprometido a conducir a Lezo, por asiento firmado en 1782, se vio obligado a comprar varias yuntas de bueyes, con el consiguiente desembolso que ello y el mantenimiento de las mismas suponía. Generalmente, era la Marina quien aportaba a los boyerizos los aparejos y carros; dichos carros eran construidos con madera de roble por parte de los asentistas, y esto también generaba numerosos conflictos, pues se cortaban para ello robles jóvenes, provocando importantes daños en los montes ${ }^{38}$.

En cualquier caso, la construcción de nuevos caminos y el acondicionamiento o perfeccionamiento de otros supuso la mejora de las comunicaciones de estos intrincados valles y facilitó el contacto con el resto del mundo de ciertas zonas de Álava, Vizcaya, Guipúzcoa o Navarra. Es más, muchos de esos nuevos caminos abrieron nuevas vías de comercio y modificaron los ejes de transporte y comunicación existentes hasta la época. Así Miguel Antonio Iriarte Belandía y Juan Miguel Zatarain, en vez de utilizar el ramal de Navarra, mucho más complicado para transportar troncos de casi 30 metros de largo, construyeron un nuevo camino carretil para la extracción de maderas de roble y el paso de pinabetes desde el Pirineo navarro, entre EcharriAranaz y Beasain, por el paso de Eizagarate (actual Etzegarate). Es decir, ambos asentistas, encargados por la Real Compañía de Caracas de la extracción en 1769 de 8.000 robles para el arsenal del Ferrol desde los montes de la Burunda, abrieron lo que en el futuro sería el paso principal de la carretera N-1, aún hoy día activo, como alternativa al mencionado ramal de Navarra, que desde Echarri-Aranaz pasaba por Ataun hasta la casa torre y ferrería de Yarza, donde también se unía al Camino Real de Coches que desde Arlaban llegaba al mencionado punto, pasando por el alto de Descarga y Zumárraga. El camino abierto por ambos asentistas bajaba desde Alsasua hacia Echegárate y de aquí a Idiazabal, para acabar uniéndose a los otros dos en la mencionada ferrería y palacio de Yarza, en Beasain (Achón Insausti, 1998) ${ }^{39}$.

\section{4. ¿FRACASO O ÉXITO? VIDAS PARALELAS}

¿Quiénes eran estos asentistas que arriesgaban sus patrimonios?¿Buscaban realmente un enriquecimiento o algo más?¿Qué les reportó el servicio a la corona?

38. AGN, Procesos 7269 (I y II); Tribunales Reales, Archivo Secreto, Tit. 33, Fajo 1, N. 1; AGN, VR_DOCUMENTOS, Leg. 47, N. 3.

39. Archivo General de Gipuzkoa (AGG-GAO), JD IM 2/19/5. 
ÁLVARO ARAGÓN-RUANO Y ÓSCAR RIEZU ELIZALDE

¿UN PROYECTO QUIMÉRICO? SUMINISTROS FORESTALES DESDE LOS PIRINEOS

OCCIDENTALES PARA LA REAL ARMADA EN EL SIGLO XVIII

Más allá de Juan de Goyeneche, cuya biografía es de sobra conocida, en esta ocasión vamos a presentar los casos de asentistas que nos pueden acercar a la realidad de esas oligarquías medias que, sin llegar a tener grandes patrimonios ni dar el salto a la Corte, permanecieron en sus lugares de origen, aunque supieron vincularse familiarmente a lo más rancio de la nobleza española, y fueron los ojos y las manos del Leviatán a nivel regional y local, es decir, quienes aplicaron la política de provisión de recursos forestales que Arriaga o González de Castejón dictaban desde Madrid. Contamos con abundantes datos referidos a dos asentistas de los que ya hemos hablado y de los que vamos a tratar de hacer una semblanza para calibrar el impacto que en sus vidas y haciendas tuvieron los asientos de madera.

Miguel Antonio Iriarte Belandía formaba parte de una saga dedicada desde el primer tercio del siglo XVIII al aporte de materiales para la Real Armada. En concreto, en ese período encontramos a Juan Iriarte Belandía y Nicolás Belandía, ambos vecinos de Urnieta, estableciendo una contrata para proveer a la corona. Dicha familia surgió de la unión entre los Iriarte y los Belandía, ambas familias de Urnieta con sus respectivas casas solares. Su principal representante fue Miguel Antonio Iriarte Belandía - hijo del mencionado Juan de Iriarte Belandía e Isabel Yurremendi-. Los Iriarte Belandía fueron una de las familias más importantes de Urnieta, villa que estaba fuertemente vinculada a la explotación forestal de los cercanos Montes Francos del Urumea y a la industria siderúrgica. En ese sentido, Miguel Antonio Iriarte Belandía, junto a Juan Miguel Zatarain, vecino de Zubieta, elevaron en 1771 un pleito contra el concejo de Hernani por el disfrute de los mencionados montes, e Iriarte Belandía remató varias porciones de leña en los años 1764 y 1794. Además de su participación en numerosas ferrerías, como por ejemplo Plazaola o Picoaga, junto a su ya por entonces cuñado Juan Miguel Zatarain, Miguel Antonio Iriarte Belandia estableció en su villa natal una fábrica de anclas, en la que fabricó, asociado con Santiago Labayen, 407 anclas en 1785 y 206 en 1786, encargadas por asiento, con destino a los reales arsenales de Cartagena. En 1776, junto a Juan Bautista Zabala y Juan Bautista Argote, vecinos de Andoain, el mencionado Juan Miguel Zatarain, Pedro José Zavala, vecino de Asteasu, y Milián Ateaga, vecino de Villabona, dieron carta de poder a favor de Diego Cruz Aozaraza, vecino de Madrid, para que hiciese puja en el asiento de herraje y clavazón de los departamentos de Ferrol, Cádiz y Cartagena. Los Iriarte Belandía se acabarían vinculando a los Zatarain, vecinos de Zubieta, dueños de la casa solar Bazcardo, que ostentaron cargos como vecinos concejiles en la vecina localidad de Asteasu y estuvieron vinculados a la actividad forestal en las localidades del entorno, a la actividad siderúrgica - Juan Miguel Zatarain arrendó y regentó una oficina de anclas en Zubieta, activa todavía en 1803-, a la actividad pesquera fluvial - con una nasa en el río Oria - y a la construcción naval - en 1781 Juan Miguel tenía ocho carpinteros en el astillero de Santa Catalina en San Sebastián, participando en la construcción de un navío-. Además en 1804 sustituyeron a los Beldarrain en la administración de los montes de Idia y Andaza, 
ÁLVARO ARAGÓN-RUANO Y ÓSCAR RIEZU ELIZALDE

¿UN PROYECTO QUIMÉRICO? SUMINISTROS FORESTALES DESDE LOS PIRINEOS

OCCIDENTALES PARA LA REAL ARMADA EN EL SIGLO XVIII

en Usúrbil - a 10 km de Urnieta-, propiedad de la Real Colegiata de Roncesvalles, de la mano de José Antonio Zatarain.

Tanto Miguel Antonio como Juan Miguel estuvieron vinculados a la provisión de madera para la Real Armada: Zatarain firmó contrata en 1759 con el rey para el aporte de 2.850 tablones de roble para la Armada; en 1766, Iriarte Belandía obtuvo la almoneda para la compra, derribo, labra y conducción de materiales a los embarcaderos de Gipuzkoa y en 1778 fue el comisionado de la Real Compañía de Caracas en la contrata para el aporte de 2.000 tablones y 500 curvas, desde los montes de Leiza, asociándose en 1782 a Zatarain para llevar a cabo una contrata para la compra, labra y conducción de maderas de roble desde los montes de Burunda y Echarri-Aranaz. Finalmente, Miguel Antonio fue nombrado en 1799 comisario de Guerra y director de la Repoblación de montes de las Reales Fábricas de Artillería de La Cavada. Muerto en marzo de 1800 dejó vínculo por valor 1.365.955 reales de vellón a su sucesor y sobrino - pues Miguel Antonio no tuvo hijos - , Miguel Domingo Zatarain Belandía, Comisario honorario de Guerra del Ministerio de Marina e inspector de caminos reales y postas del segundo partido de la provincia de Guipúzcoa, quien tuvo importantes problemas económicos, entre otras cuestiones, por las deudas que contrajeron sus tíos, Miguel Antonio Iriarte Belandía y Juan Miguel Zatarain, con comerciantes de San Sebastián, por la compra de madera, carbón para la herrería de Picoaga y anclas. De hecho, murió el 5 de marzo de 1825 agobiado por deudas por valor de 593.950 reales, contraídas con una serie de comerciantes de San Sebastián y Bilbao por la compra de cargas de carbón y diferentes hierros, y por los préstamos de dinero para la oficina de anclas de Urnieta. Según alegaba el propio Miguel Domingo - como también le ocurriría a Pedro Vicente Gambra - el parón que supuso la Guerra de la Independencia para la producción de anclas y hierro acabó por arruinarle. A su muerte, la hacienda de los Zatarain Belandía estaba compuesta por diferentes terrenos y casas localizadas en un radio de unos $15 \mathrm{~km}$ en torno a la propia Urnieta, incluyendo Andoain y San Sebastián, la mayoría de los cuales le fueron embargados a su viuda para hacer frente a las mencionadas deudas (Aragón, 2001: 121; Odriozola, 1997: 285 y 1998: 141; Carrión 1998: 569; Almanak,1803: 260 $)^{40}$.

Por su parte, Pedro Vicente Gambra Ezquer (1749-1820), vecino de Roncal, fue un comerciante y empresario relacionado con la lana y el ganado ovino, que llegaría a ser capitán de guerra del valle del Roncal durante la Guerra de la Convención. En un exhorto que publicó en 1789 - posiblemente para recordar al rey los servicios prestados en el transporte de maderas para el Canal Imperial, pero también

40. Archivo Real Chancillería de Valladolid, Pleitos Civiles, Varela, Olvidados, C 2446/2, L 816 y Zarandona y Wals, Olvidados, C 3135/1 - L 1158; AGG-GAO, PT 2740, 1, ff. 125r 127v; PT 2693, ff. 857r - 859r; COECI 4051; COCRI 354,1; CO LEJ 2610. 
ÁLVARO ARAGÓN-RUANO Y ÓSCAR RIEZU ELIZALDE

¿UN PROYECTO QUIMÉRICO? SUMINISTROS FORESTALES DESDE LOS PIRINEOS

OCCIDENTALES PARA LA REAL ARMADA EN EL SIGLO XVIII

para defenderse de las acusaciones que el valle del Roncal, su patria, vertía contra él por los daños causados por la riada de 1787- titulado "patriotismo", afirmaba que «...se ha empleado desde su niñez en las ocupaciones propias de un labrador y ganadero, y en el comercio de la lana de sus rebaños...», llegando a poseer hasta 20.000 cabezas de ovino, con las que trashumaba entre el Pirineo y áreas de pasto de Aragón, como el monte Sora (Ejea de los Caballeros, Zaragoza) o las hierbas de la dehesa de Carboniel y pastos comunes del lugar de Alfamén (Zaragoza). La lana producida por dichas ovejas era vendida a los telares de Olorón y Mauleón, donde contaba con diferentes agentes (Memorial, 1789: 421-425) . $^{41}$

En 1772 se introdujo, según su propio testimonio, en el negocio de las maderas, siguiendo así el camino iniciado por su padre, quien había vendido maderas a diversos pueblos de la Ribera. En esa línea, firmó un asiento con Plácido Correa para el acondicionamiento del río Irati entre 1779 y 1781, formando compañía con Melchor Marichalar, vecino de Urroz, y Manuel Ramón y Martín José García Herreros, vecinos de Pamplona, a fin de conducir madera desde la unión de los ríos Urbelcha y Urchuria hasta la salida del puente de Jesús. Las obras fueron tasadas en 295.000 reales de vellón, siendo su participación de dos tercios. Sin embargo, como él mismo reconocía en el mencionado exhorto, en la apertura y acondicionamiento de los ríos, rotura de peñas, formación de once puertos o rampas en puertos molineros, establecimiento de tres puertos en Irati y construcción de esclusas, se gastó 7.000 pesos fuertes. Una vez terminado este asiento, firmó otro, gracias a su amistad con Ramón Pignatelli, para proveer de madera al Canal Imperial - construido entre 1779 y 1790 -, para lo que entre abril y junio de 1782 estableció contrata para la extracción de maderas desde el monte Urralegui, con obligación de cortar y transportar 18.000 pinos en 15 años $^{42}$. Para ello tuvo que acondicionar el mencionado barranco de Urralegui, concretamente, llevó a cabo la construcción de dos esclusas, 14 presas y la rotura de diferentes peñas. Sin embargo estas infraestructuras fueron destruidas por la avenida de aguas del 24 de septiembre de 1787, lo que, junto a la madera extraviada, le supuso unas pérdidas de 40.000 pesos fuertes. Además, en el ínterin, se vio obligado a extraer árboles desde el área de San Juan de la Peña. La reparación de los daños sufridos en el sistema de Urralegui, concretamente, la habilitación de dos esclusas en Urralegui y una en Roncal de 3.000 estados cúbicos de pared cada una, le supusieron 50.000 pesos fuertes de inversión. Aunque en 1791 ya realizó algunos pequeños envíos de prueba al arsenal de Cartagena, fue en 1792 cuando firmó una contrata para la provisión de 90.000 codos cúbicos de tabla para el carenado de los barcos. Así mismo, en 1795 hizo contrata para llevar 1.500 maderos

41. Archivo Histórico Provincial de Zaragoza, J/013908/000009.

42. En un artículo previo (Aragón, 2017: 44) se vinculaba, erróneamente, este asiento a Plácido Correa y a la provisión del real arsenal de Cartagena. 
ÁLVARO ARAGÓN-RUANO Y ÓSCAR RIEZU ELIZALDE

¿UN PROYECTO QUIMÉRICO? SUMINISTROS FORESTALES DESDE LOS PIRINEOS

OCCIDENTALES PARA LA REAL ARMADA EN EL SIGLO XVIII

hasta Caparroso, para las fortificaciones de Pamplona. Por último, en 1803, siendo teniente coronel, lo encontramos visitando y peritando para la Marina los bosques de Boí y del condado de Eril, en el Pirineo catalán, donde confeccionó sendos mapas. También tuvo numerosas pérdidas en los asientos con el Canal Imperial y la Real Armada entre 1782 y 1802, pues además de no serle abonado todo el valor de las maderas, hubo de hacer frente a una veintena de pleitos con las localidades por donde pasaban las almadías, a causa de los daños realizados por las maderas (Memorial, 1789: 421-425; Silva, 2005: 471) 43. $^{4}$.

Pedro Vicente Gambra llegó a la alcaldía de Roncal en 1786 y se mantuvo en el puesto hasta la Guerra de la Convención. Durante dicho conflicto, como alcalde que era, organizó a los habitantes del valle en varias partidas y participó en varias acciones de guerra, lo que le reportó el 8 de noviembre de 1794 el nombramiento como capitán de infantería del Valle del Roncal. Posteriormente, en 1802 fue nombrado teniente coronel y, durante la Guerra de la Independencia, coronel honorario de los reales ejércitos por Palafox, quien enroló a sus hijos, Francisco y Sebastián, para la defensa de Zaragoza. Pedro Vicente, por su parte, organizó una partida que participó en el ataque a Sangüesa. Tras la capitulación del Valle vio confiscados sus propiedades, principalmente el ganado y las maderas, lo que le llevó a la ruina total. Gracias a su posición y su participación en el asiento de maderas casó a una de sus hijas con el Mariscal de Campo Mariano Renovales, afamado encartado vizcaíno. Arruinado al final de su vida por las circunstancias de la Guerra de Independencia, pidió auxilio a Fernando VII - quien no atendió su demanda-, para que se le pagasen los atrasos de las maderas provistas. Uno de los principales problemas de los asientos firmados fue que la Armada tardaba muchísimo tiempo en abonarle las remesas de madera enviada y cuando lo hacía era por medio de vales reales; eso cuando llegaba a pagar, pues en numerosas ocasiones los envíos no fueron abonados, sobre todo en períodos de conflicto. Por tanto, la Armada debía a Gambra enormes cantidades de dinero por el atraso en los pagos; por ello, durante esta última etapa de su vida, como se puede comprobar en su archivo, redactó un sinfín de cartas referidas a este asunto, pidiendo a la junta del arsenal de Cartagena que le enviase el dinero que se le adeudaba (Gambra, 1959) ${ }^{44}$.

43. AGN, Procesos 157032, 193045 (I y II) y 207475; Montes, Legajo 2, Carpeta 14; Reales tribunales, Archivo Secreto, Tit. 4, Fajo 3, N. 29 y Tit. 33, Fajo 1, N. 5; CO_PS. 1ª, Leg. 10, N. 22; ACG, Legajo 1, n. ${ }^{\circ}$ 37, Sección correspondencia, Legajo 54 (1792) y Sección documentación, Legajo 9 (1786 y 1815).

44. ACG, Sección documentación, Legajos 6 y 9 (1803), Sección correspondencia, Legajo $54(1793)$. 
ÁLVARO ARAGÓN-RUANO Y ÓSCAR RIEZU ELIZALDE

¿UN PROYECTO QUIMÉRICO? SUMINISTROS FORESTALES DESDE LOS PIRINEOS

OCCIDENTALES PARA LA REAL ARMADA EN EL SIGLO XVIII

\section{CONCLUSIONES}

A pesar de las grandes dificultades, la extracción de maderas desde el Pirineo occidental no fue una quimera. De hecho, las maderas llegaron a los reales arsenales de Ferrol, Cádiz y Cartagena - quizás fue el único área peninsular capaz de abastecer a los tres, gracias al acceso hacia el Cantábrico y el Mediterráneo-, si bien con grandes esfuerzos y, en ocasiones, con importantes retrasos, tanto en el caso de la gestión directa como en el de la indirecta. No obstante, como demuestran los casos analizados o el de la Sierra de Segura, que abastecía a Cádiz y Cartagena, la provisión de maderas a lo largo de todo el siglo XVIII estuvo presidida por cierta improvisación, precariedad, provisionalidad y lentitud. Si bien entre las ventajas del sistema estaba que el Estado veía facilitado el acceso a dichos recursos, gracias a la presencia de esos intermediarios que conocían perfectamente dichas áreas y eran capaces de movilizar los recursos humanos y económicos locales o regionales, entre los inconvenientes cabría destacar que, ante la diferencia de objetivos entre proveedores y proveídos, la incompatibilidad o choque de intereses entre los agentes locales-regionales y los estatales, la carencia de instrumental o de pericia de los operarios y la falta de competencia de los precios ofertados por la Hacienda real o los asentistas con respecto a los precios de mercado, la llegada de las maderas se ralentizó y, muchas veces, el ritmo de provisión no se adecuó al ritmo de demanda desde los reales arsenales, de ahí también que se buscasen alternativas de provisión y los arsenales no se proveyesen desde una única área. Creemos que este fue uno de los grandes problemas de la provisión de maderas a la Real Armada, la inexistencia de un plan estratégico de explotación de áreas forestales concretas, como por ejemplo sí ocurría parcialmente en el caso de Portugal o Inglaterra, donde las respectivas coronas contaban con bosques de patrimonio real de los que se surtían, por ejemplo, de piezas curvas, recurriendo a la importación de tablazón y mástiles desde el extranjero. No obstante, la mayor parte de las Marinas europeas del XVIII también tuvieron problemas de abastecimiento; concretamente, la Royal Navy, «la reina de los mares», sufrió escasez de madera a consecuencia de la indolente gestión de las autoridades navales, la venalidad del brazo civil de la Marina, el fortalecimiento del monopolio de los contratos y los vaivenes en el crédito disponible, viéndose afectada también por el progresivo agotamiento de los bosques ingleses o la precaria naturaleza del comercio báltico (Pérez-Crespo, 1992; Sánchez y Roda, 2018; Trápaga, 2019; Albion, 1926: 39-67 y 96-101). No obstante, se puede aseverar que el problema no estuvo únicamente en la provisión de madera - habría además que ponderar la cuestión de la calidad de las maderas recibidas-, sino también en su gestión y utilización en los reales arsenales.

Más aún, a pesar del establecimiento de los reales arsenales, los problemas con las comunidades locales no cejaron y, en parte, es por lo que se estableció una extensa legislación forestal. A pesar de la pertinencia de las normas establecidas, su aplicación 
ÁLVARO ARAGÓN-RUANO Y ÓSCAR RIEZU ELIZALDE

¿UN PROYECTO QUIMÉRICO? SUMINISTROS FORESTALES DESDE LOS PIRINEOS

OCCIDENTALES PARA LA REAL ARMADA EN EL SIGLO XVIII

falló, pues no se contó con el consenso y participación de las comunidades locales. En realidad, ambas economías chocaron, pues las necesidades navales fueron una competencia para el aprovechamiento rural, y generaron una importante deforestación, aunque, como se ha visto, esta no fue real hasta finales del siglo XVIII, y lo que realmente estaba detrás de las quejas en torno a la escasez de materiales era el intento por parte del Estado o de los grupos económicos de hacerse con un mayor control sobre dichos recursos. La política forestal adoleció desde el inicio de graves contradicciones e insuficiencias, que terminaron por hacerla inviable, pues si bien fue planteada como un esfuerzo repoblador y conservacionista de los bosques, la demanda - siempre demasiado perentoria - fue por delante de la capacidad natural de regeneración y la legislación tuvo una aplicación despótica, basada en la coacción y el control. Como ocurriese en el caso de los vecinos de los valles del Pas y Miera durante el siglo XVIII, muchas de estas comunidades locales llegaron a sentirse tratadas «como una Colonia de Esclavos o conquistados, que el Rey ha relegado en esta comarca para trabajar en Servicio de su Marina» (Baudot, 2012: 297-328; Diego y García, 2003: 215-220; Martínez, 2015; Urteaga, 1987).

Es cierto, además, que los asentistas tuvieron que hacer frente a una maraña inextricable de jurisdicciones y de usos y costumbres, defendidos a capa y espada por las comunidades rurales, que dependían de esas riquezas forestales -en una Monarquía compuesta (composite monarchy, multiple kingdom o dynastic agglomerate), quizás como ninguna, en la que el rey debía respetar la interminable escala de jurisdicciones e instancias decisorias, a nivel territorial y local-, así como lidiar con unos gastos que en la mayoría de los casos no consiguieron recuperar. Como hemos tenido ocasión de comprobar a través de los casos de Iriarte Belandía o Gambra -o como ejemplifican los casos de los asentistas de construcción naval en Guarnizo, Juan Fernández de Isla o Manuel de Zubiría, quienes sufrieron la bancarrota (Castanedo, 1995; Maruri, 2001) -, estos asentistas pusieron en riesgo su propia supervivencia y haciendas a cambio del servicio a la corona. Ha quedado claro que el principal objetivo no era el enriquecimiento económico, sino las prebendas sociales y políticas que reportaba el servicio a la corona. Estos hombres hechos a sí mismos (self-made $m e n)$, personajes «sin otro estudio que su propio ingenio...(empeñados)...mas en cumplir lo prometido que en sacar algun fruto de aquel trabajo rudo», como afirmaba Gambra en su exhorto de 1789, buscaban a través del servicio a la corona obtener un prestigio social y político, ante sus propios compatriotas, y el escaparate adecuado para poder vincularse con familias cortesanas de prestigio o para obtener cargos que les acercasen a tan selecto club (Memorial, 1789: 421-425) ${ }^{45}$.

45. AGN, Procesos 7270; Tribunales Reales, Archivo Secreto, Tit. 4, Fajo 3, N. 8 y Tit. 33, Fajo 1, N. 1. 
ÁLVARO ARAGÓN-RUANO Y ÓSCAR RIEZU ELIZALDE

¿UN PROYECTO QUIMÉRICO? SUMINISTROS FORESTALES DESDE LOS PIRINEOS

OCCIDENTALES PARA LA REAL ARMADA EN EL SIGLO XVIII

Gracias a eso, ese Estado compuesto logró llegar a los lugares más recónditos bajo su dominio. Es más, gracias a las infraestructuras establecidas, los caminos abiertos, las redes comerciales, laborales y personales entretejidas, consiguieron que esos entornos geográficos recuperaran el ritmo de la historia y tuviesen contacto con el resto del mundo: los operarios llegados desde zonas cercanas a la costa hasta el corazón del Pirineo trajeron consigo nuevas ideas, valores y mentalidades, nuevos productos coloniales, nuevas técnicas - si bien gracias al contrabando dichas áreas no permanecían completamente aisladas y ya habían tenido contacto con esas nuevas realidades - . La movilidad de personas y productos permitió que a lo largo del siglo XVIII el mercado español fuese un mercado mucho más integrado, más abierto y unitario. A costa de sus propias haciendas y patrimonio, además, permitieron la redistribución de la riqueza y el desarrollo económico de zonas que durante siglos habían mantenido unas economías precarias. Es cierto que la explotación maderera no solucionó problemas estructurales, pero permitió a las economías agrarias diversificarse y tener un complemento en los ingresos de esas castigadas economías campesinas. El mantenimiento de operarios requirió de la llegada de bastimentos y alimentos desde otras áreas peninsulares, bien desde el interior para el aporte de cereales, carnes y vinos, bien desde áreas costeras para la llegada de pescados o productos coloniales, como azúcar, cacao, pimienta, cera, pólvora, etc., y del desarrollo de servicios para su alojamiento, manutención o esparcimiento, beneficiando a los habitantes locales. Así mismo, los ayuntamientos consiguieron nuevas entradas de dinero gracias al cobro de peajes y al saneamiento de las economías de muchos de esos vecinos que participaban en las labores de corte, transporte terrestre o fluvial de las maderas, alojamiento y manutención.

Grandes, medianos o pequeños, estos asentistas fueron los tentáculos y los ojos del Estado, fueron el propio Estado en esos lugares de difícil acceso. Por tanto, podemos decir que fueron agentes del Estado moderno y colaboraron en su formación, construcción y fortalecimiento; ellos también hicieron Estado. Debe, en consecuencia, reivindicarse el papel de las oligarquías regionales y locales en la formación de los Estados modernos, la colaboración entre el rey y los particulares, superando la dicotomía entre lo público y lo privado, y entre centro y periferia, que son más bien construcciones contemporáneas.

\section{BIBLIOGRAFÍA}

(1789). Memorial literario, instructivo y curioso de la Corte de Madrid, Tomo XVIII. Madrid: Imprenta Real.

(1803). Almanak mercantil o guía de comerciantes para el año 1803. Madrid: Imprenta de la calle de Capellanes. 
ÁLVARO ARAGÓN-RUANO Y ÓSCAR RIEZU ELIZALDE

¿UN PROYECTO QUIMÉRICO? SUMINISTROS FORESTALES DESDE LOS PIRINEOS

OCCIDENTALES PARA LA REAL ARMADA EN EL SIGLO XVIII

Achón Insausti, J. A. (1998). Historia de las vías de comunicación en Gipuzkoa, 2: Edad Moderna (1500-1833). San Sebastián: Diputación Foral de Gipuzkoa.

Albion, R. G. (1926). Forests and Sea Power: the Timber Problem of the Royal Navy. 1652-1862. Cambridge: Harvard University Press.

Aquerreta, S. (2000). Negocios y finanzas en el siglo XVIII: la familia Goyeneche. Pamplona: Eunsa.

Aragón Ruano, Á. (2001). El bosque guipuzcoano en la Edad Moderna: aprovechamiento, ordenamiento legal y conflictividad. San Sebastián: Sociedad de Ciencias Aranzadi.

Aragón Ruano, Á. (2017). Mar de árboles, vorágine de jurisdicciones. La complicada relación entre la Real Armada española y los bosques del Pirineo Occidental peninsular en el siglo XVIII. En R. Varela Gomes y K. Trapaga Monchet (eds.), Árbores, barcos e bomens na Península Ibérica (séculos XVI-XVIII) [ForSEADiscovery Project (PITNGA-2013-607545)] (pp. 45-52). Lisboa: Instituto de Arqueologia e Paleociências da Universidade Nova de Lisboa.

Aragón Ruano, Á. (2019). Un choque de jurisdicciones. Fueros y política forestal en el Pirineo occidental durante el siglo XVIII. Obradorio de Historia Moderna, 28, 135-162.

Aragón Ruano, A., Reichert, R., Wing, J. T. (2019). Maderas para el rey: avances, resultados, propuestas. Obradoiro de Historia Moderna, 28, 7-26.

Baudot Monroy, M. (2012). Barcos para el rey. Julián de Arriaga, la madera y la construcción naval (1752-1759). En M. R. García Hurtado (ed.), La Armada española en el siglo XVIII (pp. 297-328). Ciencia, hombres y barcos. Madrid: Sílex.

Baudot Monroy, M. (2019). La política naval española entre 1700 y 1736. La recuperación del poder naval de la Monarquía. Tempus Revista en Historia General, 9, 1-50.

Carrión Arregui, I. M. (1998). La fabricación de grandes anclas de navíos en el siglo XVIII en Gipuzkoa. Itsas Memoria, 2, 549-571.

Castanedo Galán, J. M. (1995). Un asiento singular de Juan Fernández de Isla. La fábrica de ocho navíos y la reforma de un astillero. En C. Martínez Shaw (ed.), El Derecho y el Mar en la España Moderna (pp. 457-476). Granada: Universidad de Granada Centre D’Estudis D’Historia Moderna Pierre Vilar.

Castellano de Gastón, G. (2007). Los Gastón de Iriarte: trayectoria de una casa baztanesa (siglos XVI-XIX). Pamplona: Eunate.

Diego Liaño, C. y García Cordón, J. C. (2003). La Corona y los pueblos en la explotación de los montes de Cantabria: Deforestación y gestión del bosque en la segunda mitad del siglo XVIII. Cuadernos de la Sociedad Española de Ciencias Forestales, 16, 215-220.

Gambra, R. (1959). El Valle de Roncal en la Guerra dela Independencia. Los orígenes de la Guerra en Navarra y el «proyecto secreto». Príncipe de Viana, Año XX, n. ${ }^{\circ}$ 76-77, 187-215.

González, J. (2004). La Carraca. El primer arsenal ilustrado español (1717-1776). Madrid: Ministerio de Defensa, Instituto de Historia y Cultura Naval. 


\section{ÁLVARO ARAGÓN-RUANO Y ÓSCAR RIEZU ELIZALDE ¿UN PROYECTO QUIMÉRICO? SUMINISTROS FORESTALES DESDE LOS PIRINEOS OCCIDENTALES PARA LA REAL ARMADA EN EL SIGLO XVIII}

Iturrate, J. (2001-2003). Elaboración de remos de mar y extracción de madera para navíos reales en los montes de Gorbea (Alava), País Vasco. Documentos varios. (S. XVIIXVIII). Kobie (Serie Antropología Cultural), 10, 117-128.

López Arandia, M. A. (2017). Maderas para el Real Servicio y el bien común. Aprovechamientos forestales en la provincia marítima de Segura de la Sierra (ss. XVIII-XIX). En R. Varela Gomes y K. Trápaga Monchet (eds.), Árvores, bracos e homens na Península Ibérica (Séculos XVI-XVIII) (pp. 25-40). Lisboa: Instituto de Arqueologia e Paleociencias - Instituto de História Contemporánea, 25-40.

López Arandia, M. A. (2018). Aprovisionando de madera el arsenal de Cartagena: el proyecto de Manuel Bernia y las flotaciones por el río Segura (784-1793). Tiempos Modernos, 36, 127-168.

Martínez González, A. J. (2015). Masas forestales para las Armadas: las áreas jurisdiccionales de montes y plantíos (siglos XVI-XVIII).Naveg@mérica. Revista electrónica editada por la Asociación Española de Americanistas, 14.

Maruri Villanueva, R. (2001). Ensenada y el Real Astillero de Guarnizo, Brocar, 25, 123-136.

Merino Navarro, J. P. (1981). La armada española en el siglo XVIII. Madrid: Fundación Universitaria Española.

Odriozola Oyarbide, L. (1997). La construcción naval en Gipuzkoa, siglo XVIII. San Sebastián: Diputación Foral de Gipuzkoa.

Odriozola Oyarbide, L. (1998). La construcción naval en Gipuzkoa. Siglos XVI-XVIII. Itsas Memoria, 2, 93-146.

Odrizola Oyarbide, L. (2008). El bosque de Irati y el transporte de las maderas hasta los Reales Arsenales de Marina (Segunda mitad del Siglo XVIII). BRSBAP, 64, 2, 845-863.

Pérez-Crespo Muñoz, M. T. (1992). El arsenal de Cartagena en el siglo XVIII. Madrid: Editorial Naval.

Quintero González, J. (2004). La Carraca. El primer arsenal ilustrado español (1717-1776). Madrid: Ministerio de Defensa, Instituto de Historia y Cultura Naval.

Sánchez Baena, J. J. y Roda Alcantud, C. (2018). El Arsenal del Mediterráneo. Cartagena (1750-1824). En J. Marchena y J. Cuño, Justo (eds.), Vientos de Guerra. Apogeo y crisis de la Real Armada, 1750-1823. vol. 3. Los Arsenales, el Pacífico, la vida a bordo (pp. 117-198). Sevilla: Junta de Andalucía - Universidad Pablo Olavide - Doce Calles.

Sanz Ayánz, C. (2004). Estado, Monarquía y finanzas. Estudios de Historia financiera en tiempos de los Austrias. Madrid: Centro de Estudios políticos y constitucionales.

Silva Suárez, M. (ed.). (2005). Técnica e ingeniería en España, III, El siglo de las luces. De la industria al ámbito agroforestal. Zaragoza: Institución «Fernando El Católico».

Trápaga Monchet, K. (2019). No es madera para vasallos, sino del rey: las políticas forestales de los Habsburgo en Portugal (1609-1640). Obradoiro de Historia Moderna, 28, 105-134. 
ÁLVARO ARAGÓN-RUANO Y ÓSCAR RIEZU ELIZALDE

¿UN PROYECTO QUIMÉRICO? SUMINISTROS FORESTALES DESDE LOS PIRINEOS

OCCIDENTALES PARA LA REAL ARMADA EN EL SIGLO XVIII

Urteaga, L. (1987). La tierra esquilmada. Las ideas sobre la conservación de la naturaleza en la cultura española del siglo XVIII. Madrid: Serbal/CSIC.

Váldez-Bubnov, I. (2011). Poder naval y modernización del Estado: política de construcción naval española, siglos XVI-XVIII. México: Universidad Nacional Autónoma de México.

Vázquez Lijó, J. M. (2018). El Arsenal de Ferrol: un derrotero del esplendor al ocaso (17501820). En J. Marchena y J. Cuño (eds.), Vientos de Guerra. Apogeo y crisis de la Real Armada, 1750-1823, vol. 3. Los Arsenales, el Pacífico, la vida a bordo (pp. 9-116). Sevilla: Junta de Andalucía - Universidad Pablo Olavide - Doce Calles.

Warde, P. (2006). Fear of Wood shortage and the reality of the Woodland in Europe, c. 1450-1850. History Workshop Journal, 62, 39-41.

Warde, P. (2015). Early Modern «Resource Crisis»: The Wood shortage debates in Europe. En A. T. Brown, A. Burn y R. Dogherty, Crises in Economic and Social History. A comparative perspective (pp. 137-160). Woodbrige: The Boydell Press. 